\title{
Microphysical simulations of sulfur burdens from stratospheric sulfur geoengineering
}

\author{
J. M. English ${ }^{1, *}$, O. B. Toon ${ }^{2}$, and M. J. Mills ${ }^{3}$ \\ ${ }^{1}$ Laboratory for Atmospheric and Space Physics, Department of Atmospheric and Oceanic Sciences, UCB 392, University of \\ Colorado, Boulder, CO 80303, USA \\ ${ }^{2}$ Laboratory for Atmospheric and Space Physics, Department of Atmospheric and Oceanic Sciences, UCB 600, University of \\ Colorado, Boulder, CO 80303, USA \\ ${ }^{3}$ NCAR Earth System Laboratory, National Center for Atmospheric Research, 3450 Mitchell Lane, Boulder, CO 80301, USA \\ *now at: NCAR Earth System Laboratory, National Center for Atmospheric Research, 1850 Table Mesa Drive, Boulder, CO \\ 80305, USA
}

Correspondence to: J. M. English (jayenglish@gmail.com)

Received: 19 December 2011 - Published in Atmos. Chem. Phys. Discuss.: 25 January 2012

Revised: 28 April 2012 - Accepted: 8 May 2012 - Published: 31 May 2012

\begin{abstract}
Recent microphysical studies suggest that geoengineering by continuous stratospheric injection of $\mathrm{SO}_{2}$ gas may be limited by the growth of the aerosols. We study the efficacy of $\mathrm{SO}_{2}, \mathrm{H}_{2} \mathrm{SO}_{4}$ and aerosol injections on aerosol mass and optical depth using a three-dimensional general circulation model with sulfur chemistry and sectional aerosol microphysics (WACCM/CARMA). We find increasing injection rates of $\mathrm{SO}_{2}$ in a narrow band around the equator to have limited efficacy while broadening the injecting zone as well as injecting particles instead of $\mathrm{SO}_{2}$ gas increases the sulfate burden for a given injection rate, in agreement with previous work. We find that injecting $\mathrm{H}_{2} \mathrm{SO}_{4}$ gas instead of $\mathrm{SO}_{2}$ does not discernibly alter sulfate size or mass, in contrast with a previous study using a plume model with a microphysical model. However, the physics and chemistry in aircraft plumes, which are smaller than climate model grid cells, need to be more carefully considered. We also find significant perturbations to tropospheric aerosol for all injections studied, particularly in the upper troposphere and near the poles, where sulfate burden increases by up to 100 times. This enhanced burden could have implications for tropospheric radiative forcing and chemistry. These results highlight the need to mitigate greenhouse gas emissions rather than attempt to cool the planet through geoengineering, and to further study geoengineering before it can be seriously considered as a climate intervention option.
\end{abstract}

\section{Introduction}

Although continued emission of greenhouse gases is very likely to cause future climate change, international agreements to limit emissions have so far failed and greenhouse gas concentrations continue to rise (IPCC, 2007). Even if carbon emissions are eliminated completely in the next 10 years, significant climate change is still possible due to the thousand-year lifetime of carbon dioxide in the atmosphereocean system and the long lag-time of the response of the climate system to the greenhouse gases that have already been added to the atmosphere (Solomon et al., 2010). Concern about future climate changes has inspired increased attention to various schemes to engineer the climate on a global scale, dubbed "geoengineering". Geoengineering could potentially be used to counteract expected greenhouse gas warming as well as severe and unforeseen perturbations to the earth's climate system as it responds to global warming. One type of geoengineering involves removal of carbon dioxide from the atmosphere. Another class, which we consider here, involves reducing the input of solar radiation in order to cool the planet. Unfortunately, solar radiation management would not remedy other consequences of $\mathrm{CO}_{2}$ emissions, such as ocean acidification (Honisch et al., 2012).

One solar radiation management method that is receiving increased attention, originally proposed by Budyko (1974, 1977), involves injecting gases into the stratosphere that 
condense to form reflective sulfate aerosols (Dickinson, 1996; Crutzen, 2006). Stratospheric injection is more effective than tropospheric injection because the stratospheric aerosol has a longer lifetime and therefore a smaller injection rate can be used. Volcanoes act as natural tests to this idea. The June 1991 eruption of Mt. Pinatubo injected roughly $10 \mathrm{Tg} \mathrm{S}$ in the form of $\mathrm{SO}_{2}$ into the stratosphere (Read et al., 1993; Krueger et al., 1995). A reduction in net radiative flux of 3 to $10 \mathrm{~W} \mathrm{~m}^{-2}$ was measured in summer and fall 1991 (Minnis et al., 1993), and surface temperatures dropped by $0.5^{\circ} \mathrm{C}$ the following year (Dutton and Christy, 1992). Using volcanoes as an analog to geoengineering can be misleading, however, because volcanic cloud lifetimes are shorter than typical climate response times (Pollack et al., 1976), and because of possible microphysical differences between the injection rate and location.

Initial stratospheric geoengineering simulations using General Circulation Models (GCMs) found a linear association between $\mathrm{SO}_{2}$ injection magnitude, sulfate burden, and temperature reduction (Rasch et al., 2008; Robock et al., 2008). However, these simulations used prescribed size distributions based on observations following the Pinatubo eruption, despite indications from a 1-D microphysical sectional model that the climate effects of stratospheric injections may be self-limiting due to particle growth (Pinto et al., 1989). More recently, climate simulations have been completed that include the microphysics of particle growth. Heckendorn et al. (2009) fed calculations from a 2-D microphysical model simulating nucleation, growth, and coagulation to a GCM. Their model simulations using an $\mathrm{SO}_{2}$ injection at the equator and a pressure altitude of $50 \mathrm{hPa}$ resulted in aerosols that grew to more than twice the size of those from Mt Pinatubo, resulting in a significantly lower particle lifetime and lower radiative forcing. Niemeier et al. (2010) used a middle atmosphere GCM coupled with a microphysical modal model with nucleation, condensation, and coagulation, and predicted that injecting $\mathrm{SO}_{2}$ at $30 \mathrm{hPa}$ instead of $50 \mathrm{hPa}$ increases aerosol burden by about $50 \%$. They assumed a size distribution represented in lognormal modes. Hommel and Graf (2011) used an uncoupled microphysical sectional model with nucleation, growth, and coagulation in zero-dimensional space and found a similar sulfate burden as Heckendorn et al. (2009) and Niemeier et al. (2010). Pierce et al. (2010) suggested injection of $\mathrm{H}_{2} \mathrm{SO}_{4}$ vapor instead of $\mathrm{SO}_{2}$ as a method to increase sulfate burden. $\mathrm{SO}_{2}$ converts to $\mathrm{H}_{2} \mathrm{SO}_{4}$ over time scales on the order of weeks, and the $\mathrm{H}_{2} \mathrm{SO}_{4}$ vapor, or the particles newly nucleated from the vapor, tend to get scavenged by already existing large particles, making them grow even larger. While the $\mathrm{SO}_{2}$ is broadly distributed in the stratosphere due to its relatively long lifetime, $\mathrm{H}_{2} \mathrm{SO}_{4}$ condenses to sulfate aerosol on the order of hours, possibly restricting the portion of the stratosphere affected by the injection directly, minimizing the peak particle size and increasing sulfate burden. Pierce et al. used a 2-D aerosol plume model to simulate the $\mathrm{H}_{2} \mathrm{SO}_{4}$ conversion to particles, in conjunction with a 2-D GCM for their simulations. When handing off the plume model output to the GCM after 24-h, they injected particles prescribed using a lognormal size distribution with a specified peak size. When injecting $\mathrm{H}_{2} \mathrm{SO}_{4}$ as particles using the plume model, sulfate burden nearly doubled relative to an $\mathrm{SO}_{2}$ injection by Heckendorn et al. (2009). About half of this improvement was due to modifying the size distribution by using the plume model, and the other half due to broadening the injection zone relative to that used by Heckendorn et al. (2009).

Study of the impacts of stratospheric geoengineering on tropospheric aerosol is much more limited than studies of stratospheric aerosol. Kravitz et al. (2009) found that stratospheric $\mathrm{SO}_{2}$ injection produced increased acid deposition especially in high latitudes, but the geoengineering contribution was much smaller than from tropospheric anthropogenic $\mathrm{SO}_{2}$ emissions, and two orders of magnitude too small to cause ecological harm. Niemeier et al. (2010) predicted increased burden in the upper troposphere or lower stratosphere region, but did not quantify the tropospheric perturbations.

Here, we discuss the first simulations using a 3-D sectional aerosol model coupled to a GCM comparing injections of $\mathrm{SO}_{2}$ gas, $\mathrm{H}_{2} \mathrm{SO}_{4}$ gas, and $\mathrm{SO}_{4}^{2-}$ particles in two different regions: a narrow band around the equator similar to that of Heckendorn et al. (2009), and a broader injection region similar to that assumed by Pierce et al. (2010). We study the impact of the type of species injected and the size of the injection zone on stratospheric aerosol burden and tropospheric aerosol burden.

\section{Methods}

\subsection{Model}

We use the Whole Atmosphere Community Climate Model (WACCM) (Garcia et al., 2007) coupled with the Community Aerosol and Radiation Model for Atmospheres (CARMA) (Toon et al., 1988). This basic framework has been used to study sulfate nucleation (English et al., 2011), dust (Su and Toon, 2011), sea salt (Fan and Toon, 2011), noctilucent clouds (Bardeen et al., 2010), meteoric dust (Bardeen et al., 2008), and black carbon (Mills et al., 2008; Ross et al., 2010). Although CARMA is capable of interacting radiatively and chemically with WACCM, for these studies the interactions were mainly disabled. This version of WACCM/CARMA utilizes Stratospheric Aerosol and Gas Experiment (SAGE) II sulfate surface area densities for radiative transfer and ozone heterogeneous chemistry calculations (Considine et al., 2000). A detailed description of this specific model is presented by English et al. (2011).

For these simulations we employ $4^{\circ}$ latitude by $5^{\circ}$ longitude horizontal resolution with 66 vertical levels. A 63species chemistry module is implemented that includes 
Table 1. Description of simulations completed.

\begin{tabular}{|c|c|c|c|c|}
\hline Simulation & Species & Injection(s) & Injection Region & Similar to \\
\hline $\mathrm{SO}_{2}$ narrow & $\mathrm{SO}_{2}$ gas & $\begin{array}{l}1,2,5,10 \mathrm{Tg} \mathrm{S} \mathrm{yr}^{-1} \text {, } \\
\text { continuous }\end{array}$ & $\begin{array}{l}4^{\circ} \mathrm{N}-4^{\circ} \mathrm{S}, \text { all lon, } \\
18.8-19.9 \mathrm{~km}\end{array}$ & Heckendorn et al. (2009) \\
\hline $\mathrm{SO}_{4}^{2-}$ narrow & $\begin{array}{l}\text { Hydrated sulfuric acid } \\
\text { droplets }\end{array}$ & $\begin{array}{l}10 \mathrm{Tg} \mathrm{S} \mathrm{yr}^{-1}, \text { continuous, } \\
\text { lognormal width } 1.5, \\
100 \mathrm{~nm} \text { peak radius }\end{array}$ & $\begin{array}{l}4^{\circ} \mathrm{N}-4^{\circ} \mathrm{S}, \text { all lon, } \\
18.8-19.9 \mathrm{~km}\end{array}$ & - \\
\hline $\mathrm{SO}_{2}$ broad & $\mathrm{SO}_{2}$ gas & $10 \mathrm{Tg} \mathrm{S} \mathrm{yr}^{-1}$, continuous & $\begin{array}{l}32^{\circ} \mathrm{N}-32^{\circ} \mathrm{S}, \text { all lon, } \\
19.9-24.6 \mathrm{~km}\end{array}$ & Pierce et al. $(2010)^{\mathrm{a}}$ \\
\hline $\mathrm{SO}_{4}^{2-}$ broad & $\begin{array}{l}\text { Hydrated sulfuric acid } \\
\text { droplets }\end{array}$ & $\begin{array}{l}10 \mathrm{Tg} \mathrm{S} \mathrm{yr}^{-1}, \text { continuous, } \\
\text { lognormal width } 1.5, \\
100 \mathrm{~nm} \text { peak radius }\end{array}$ & $\begin{array}{l}32^{\circ} \mathrm{N}-32^{\circ} \mathrm{S} \text {, all lon, } \\
19.9-24.6 \mathrm{~km}\end{array}$ & Pierce et al. (2010) ${ }^{\mathrm{a}}$ \\
\hline $\mathrm{H}_{2} \mathrm{SO}_{4}$ broad & $\mathrm{H}_{2} \mathrm{SO}_{4}$ gas & $10 \mathrm{Tg} \mathrm{S} \mathrm{yr}^{-1}$, continuous & $\begin{array}{l}32^{\circ} \mathrm{N}-32^{\circ} \mathrm{S} \text {, all lon, } \\
19.9-24.6 \mathrm{~km}\end{array}$ & Pierce et al. $(2010)^{\mathrm{a}}$ \\
\hline $\mathrm{SO}_{4}^{2-}$ plume & $\begin{array}{l}\text { Hydrated sulfuric acid } \\
\text { droplets }\end{array}$ & $\begin{array}{l}10 \mathrm{Tg} \mathrm{S} \mathrm{yr}^{-1}, \text { continuous, } \\
\text { lognormal width } 1.5, \\
100 \mathrm{~nm} \text { peak radius }\end{array}$ & $\begin{array}{l}4^{\circ} \mathrm{N}-4^{\circ} \mathrm{S} \\
135^{\circ} \mathrm{E}-145^{\circ} \mathrm{E} \\
18.8-19.9 \mathrm{~km}\end{array}$ & - \\
\hline Pinatubo & $\mathrm{SO}_{2}$ gas & $\begin{array}{l}10 \mathrm{Tg} \mathrm{S} \mathrm{yr}^{-1}, 48 \text {-h burst on } \\
14-15 \text { June of year } 2\end{array}$ & $\begin{array}{l}16^{\circ} \mathrm{N}-4^{\circ} \mathrm{S}, \quad 92.5^{\circ} \mathrm{E}- \\
117.5^{\circ} \mathrm{E}, \text { semi- } \\
\operatorname{lognormal}^{\mathrm{b}}\end{array}$ & Heckendorn et al. (2009) \\
\hline Unperturbed & - & - & - & - \\
\hline
\end{tabular}

WACCM's standard 56-species chemical package. We have added 7 sulfur-bearing gases: $\mathrm{S}, \mathrm{SO}, \mathrm{SO}_{2}, \mathrm{SO}_{3}, \mathrm{HOSO}_{2}$, $\mathrm{H}_{2} \mathrm{SO}_{4}$, and OCS (English et al., 2011). The model includes emissions of carbonyl sulfide (OCS) and sulfur dioxide $\left(\mathrm{SO}_{2}\right)$, two primary sulfur emissions of importance to the stratosphere. OCS is specified with a constant surface concentration of 510 pptv. $\mathrm{SO}_{2}$ is specified from a two-dimensional monthly mean surface emissions dataset (Lamarque et al., 2010; Smith et al., 2011). Wet deposition for all constituents (including the aerosol bins from CARMA) is calculated using WACCM's existing techniques (Barth et al., 2000). All of the aerosol bins are assumed to have a constant 0.3 solubility parameter. WACCM treats dry deposition of gases (Barth et al., 2000), while dry deposition of aerosols is not considered in our simulations. Prior work has found wet deposition to be responsible for about $90 \%$ of the sulfate sink in troposphere (Textor et al., 2006); however, the absence of dry deposition in our model may impact sulfate concentrations in the boundary layer.

Binary homogeneous nucleation of sulfuric acid and water is calculated following the technique of Zhao and Turco (1995). We specify 42 sulfuric acid mass bins in CARMA ranging from $0.2 \mathrm{~nm}$ to $2.6 \mu \mathrm{m}$ dry radius, with mass doubling between bins. Since the bins only carry sulfuric acid, the equivalent sulfate aerosol size (sulfuric acid plus water) is determined by the technique of Tabazadeh et al. (1997), which calculates equilibrium weight percent sulfuric acid as a function of temperature and water activity. Weight percent sulfuric acid is assumed to be independent of particle size. The particles are assumed to have spherical shape. Split-time stepping is enabled for nucleation and growth routines when sulfuric acid is supersaturated. Nucleation and growth are treated simultaneously in the model. If sulfuric acid gas concentrations become unstable (negative), the CARMA time step is retried with double the number of substeps. Additionally, we limited nucleation so that it did not consume more than $40 \%$ of the sulfuric acid available. While our numerical model is stable, we have not done numerical tests of the accuracy of this treatment of nucleation. Since nucleation rates are very sensitive to supersaturation it is difficult to accurately predict the numbers of particles formed. However, English et al. (2011) show that even order of magnitude differences in the nucleation rates make little difference to the numbers of particles larger than about $10 \mathrm{~nm}$, because even at these small sizes the particle concentrations are controlled by coagulation. Sulfuric 


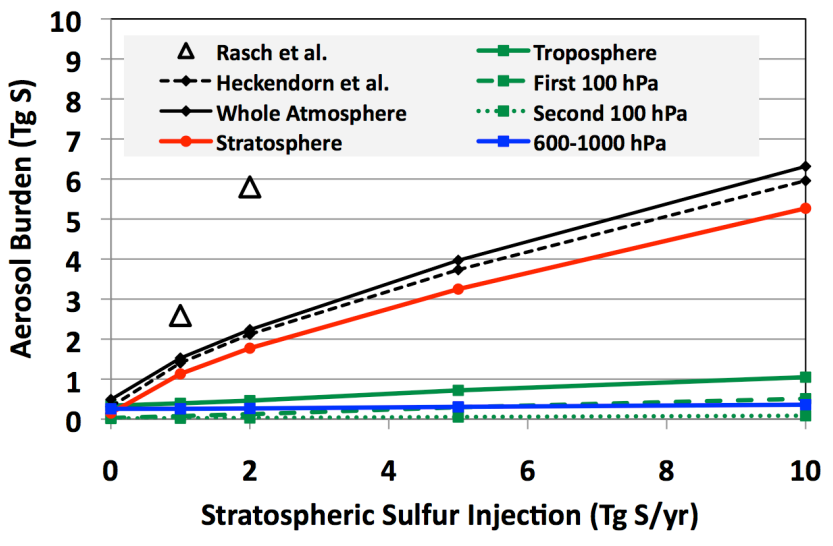

Fig. 1. Sulfate aerosol burden as a function of $\mathrm{SO}_{2}$ injection for the specified regions. Our scenarios inject $\mathrm{SO}_{2}$ between $4^{\circ} \mathrm{S}$ and $4^{\circ} \mathrm{N}$ in the $18.8-19.9 \mathrm{~km}$ grid box at all longitudes. "Whole Atmosphere" represents a direct comparison to Heckendorn et al. (2009) and Rasch et al. (2008). "First $100 \mathrm{hPa"} \mathrm{represents} \mathrm{the} \mathrm{region} \mathrm{span-}$ ning from the tropopause to $100 \mathrm{hPa}$ below the tropopause. "Second $100 \mathrm{hPa}$ " spans $100 \mathrm{hPa}$ below the tropopause to $200 \mathrm{hPa}$ below the tropopause. "600-1000 hPa" spans from $600 \mathrm{hPa}$ to the surface. See text for method of identifying tropopause.

acid surface tension is calculated using the constants from Sabinina and Terpugow (1935). We did not include any other types of aerosols. Coagulation coefficients are calculated to include Brownian, convective and gravitational effects. A sticking coefficient of 1 is used, which assumes that all particles stick together upon colliding. A correction for the impact of inter-particle Van der Waals forces on coagulation is included (Chan and Mozurkewich, 2001) which has been found to be important to accurately represent stratospheric aerosol concentrations (English et al., 2011). Sulfate aerosol growth and evaporation is calculated using sulfuric acid equilibrium vapor pressure over a binary solution computed from the method of Ayers et al. (1980) with a temperature correction by Kulmala (1990) and thermodynamic constants from Giauque (1959).

\section{Experimental design}

We investigate a series of $\mathrm{SO}_{2}$ injection rates, as well as a comparison between narrow and broad injection zones, and a comparison of injection species (Table 1). All simulations were run from the same initialization file. All simulations except Pinatubo were run for 5 years, with the 5th year analyzed. Stratospheric steady-state aerosol burdens were achieved by the second simulation year. The Pinatubo simulation was run for 6 months before its eruption was simulated on 14-15 June, and the following year (16 June of year 1 through 15 June of year 2) is compared to the other simulations.
Simulations are conducted in two latitudinal regions centered at the equator: an 8 degree wide zone similar to that specified by Heckendorn et al. (2009) and a 64 degree wide zone similar to that specified by Pierce et al. (2010), and two longitudinal regions: all longitudes similar to that specified by Heckendorn et al. (2009) and Pierce et al. (2010) as well as an 8 degree wide zone to compare to the plume studies of Pierce et al. (2010). We study the efficacy of injecting three different species: $\mathrm{SO}_{2}$ gas similar to Heckendorn et al. (2009), $\mathrm{SO}_{4}^{2-}$ aerosol injection similar to Pierce et al. (2010), and an injection of $\mathrm{H}_{2} \mathrm{SO}_{4}$ gas to compare to Pierce et al. (2010). Finally, we compare to simulations of a Pinatubo eruption and an unperturbed stratosphere.

\section{Geoengineering efficacy}

Here we consider three issues: The effect of injection rate on mass loading and optical depth; the effect of geographic distribution of the injection on mass loading and optical depth; and the effect of the material injected on mass loading and optical depth.

\section{1 $\mathrm{SO}_{2}$ injection rates}

Figure 1 (solid black line) compares steady-state atmospheric sulfate burdens for a limited spatial injection region $\left(4^{\circ} \mathrm{N}-\right.$ $4^{\circ} \mathrm{S}$ and $\left.18.8-19.9 \mathrm{~km}\right)$ and a range of $\mathrm{SO}_{2}$ injection rates $(0$, $1,2,5$, and $10 \mathrm{Tg} \mathrm{yr}^{-1} \mathrm{~S}$ ). We find the relationship between sulfate mass burden and $\mathrm{SO}_{2}$ injection rate is non-linear with reduced efficacy at higher injection rates. To achieve a $6 \mathrm{Tg} S$ burden, an injection rate of $10 \mathrm{Tg} \mathrm{S} \mathrm{yr}^{-1}$ is required, which is within $10 \%$ of the injection rate predicted by other studies that calculated aerosol size distributions (Heckendorn et al., 2009; Hommel and Graf, 2011; Niemeyer et al., 2010 (not shown)). This injection rate to obtain $6 \mathrm{Tg} \mathrm{S}$ burden is five times higher than the injection rate predicted by simulations that assumed prescribed size distributions (Rasch et al., 2008). As pointed out by others, for a given injection rate the aerosol mass burden is reduced when microphysics is treated because the larger particles that occur in the simulations fall out more quickly than the smaller ones assumed in simulations that don't treat microphysics, and radiative forcing is further reduced due to a decrease of mass extinction efficiency (Heckendorn et al., 2009).

Our simulations with varying $\mathrm{SO}_{2}$ injections have their peak aerosol optical depth (AOD) (Fig. 2) and sulfate column mass (Fig. 3) near the equator, corresponding to the injection zone. The ten-fold increase in $\mathrm{SO}_{2}$ mass injected between the $1 \mathrm{Tg} \mathrm{S} \mathrm{yr}^{-1}$ and the $10 \mathrm{Tg} \mathrm{S} \mathrm{yr}^{-1}$ simulations increases peak AOD by factors of only 2.8 at $525 \mathrm{~nm}$ and 3.1 at $1024 \mathrm{~nm}$ (Fig. 2). Similarly, peak zonal average sulfate column mass (at the equator) increases by only a factor of 5 for a ten-fold increase in injection rate (Fig. 3). AOD increases less than column mass because in addition to being 

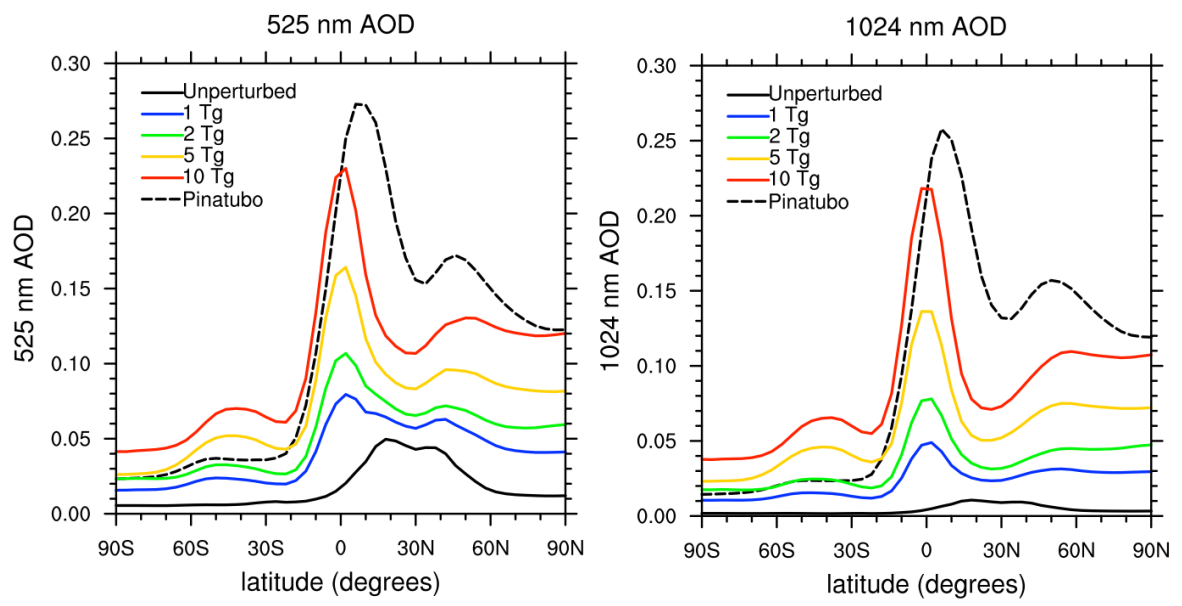

Fig. 2. Annual zonal average of sulfate aerosol optical depth (AOD) at 525 and $1024 \mathrm{~nm}$ wavelength for each of the $\mathrm{SO}_{2}$ injection scenarios (average of year 5) and for Pinatubo (average of the 1-year period starting immediately after the 15 June eruption). Extinction coefficients are calculated as a function of weight percent and wavelength using the refractive indices of Palmer and Williams (1975).
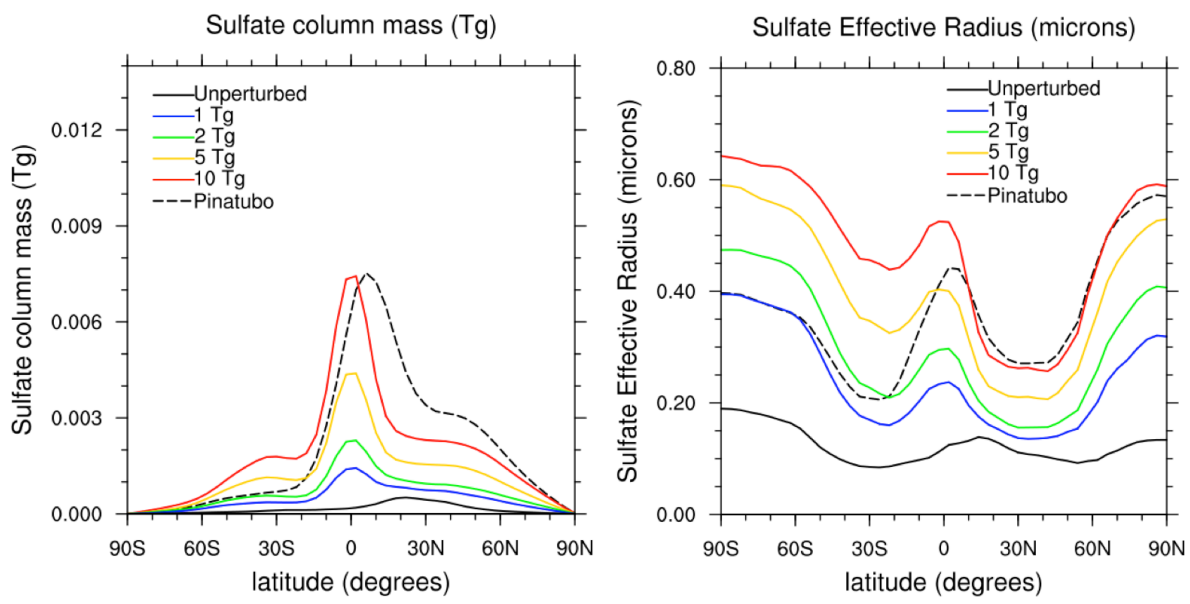

Fig. 3. Annual zonal average of sulfate column mass $(\mathrm{Tg})$ and hydrated sulfate effective radius ( $\mu \mathrm{m})$ for each of the $\mathrm{SO}_{2}$ injection $\mathrm{scenarios}$ (average of year 5) and for Pinatubo (average of the 1-year period starting immediately after the June 15 eruption). Column mass is reported per grid box ( $4^{\circ}$ latitude by $5^{\circ}$ longitude). Effective radius is a column average weighted by the aerosol surface area in each grid box to apply a fair weighting to grid boxes with more surface area.

proportional to column mass, AOD is also inversely proportional to the particle radius for particles of the sizes considered here. Effective radius (Fig. 3), defined as the ratio of the third moment to the second moment of the aerosol size distribution, increases as injection rate increases at all latitudes. We weighted the effective radius by dividing the aerosol surface area in each grid box by the total vertically integrated surface area to normalize by the amount of aerosol in each grid box. Surface area was chosen to provide a consistent weighting to the denominator of the definition of effective radius. These trends are illustrated more clearly when plotting averages in the tropics $\left(30^{\circ} \mathrm{S}\right.$ to $\left.30^{\circ} \mathrm{N}\right)$ as a function of injection rate (Fig. 4). Between the $1 \mathrm{Tg}$ simulation and the $10 \mathrm{Tg}$ simulation, effective radius nearly triples, column mass increases by a factor of 4, and 525 and $1024 \mathrm{~nm}$ AOD increase by a factor of 3 . Hence, relative to models that do not treat microphysics, the optical depth is reduced not only because the mass burden is reduced, but also because the particle size increases when microphysics is treated. Therefore $\mathrm{SO}_{2}$ injections may have limited efficacy for optical depth at higher injection rates.

The geoengineering simulations just discussed had a constant $\mathrm{SO}_{2}$ injection rate. We also compare to a simulated eruption of Mount Pinatubo. Since the Pinatubo injection is a pulse, it results in a cloud whose properties evolve in time, so it is difficult to compare with the steady state geoengineering cases. We find the Pinatubo zonal-average $525 \mathrm{~nm}$ AOD peaks about 3 months after the eruption at about 0.46 at 


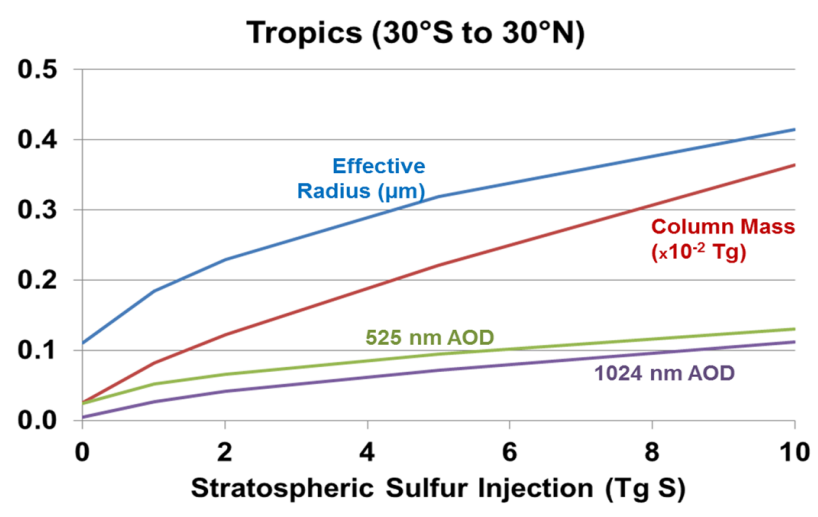

Fig. 4. Hydrated sulfate aerosol effective radius $(\mu \mathrm{m})$, column mass $\left(10^{-2} \mathrm{Tg} /\right.$ grid box $)$, and AOD at $525 \mathrm{~nm}$ and $1024 \mathrm{~nm}$ in the tropics $\left(30^{\circ} \mathrm{S}\right.$ to $\left.30^{\circ} \mathrm{N}\right)$ for each of the $\mathrm{SO}_{2}$ injection scenarios. The scenarios inject $\mathrm{SO}_{2}$ between $4 \mathrm{~S}$ and $4 \mathrm{~N}$ in the $18.8-19.9 \mathrm{~km}$ grid box at all longitudes. Column mass is reported per grid box ( $4^{\circ}$ latitude by $5^{\circ}$ longitude). Effective radius is a column average weighted by the aerosol surface area in each grid box vertically to apply a fair weighting to grid boxes with more surface area. Extinction coefficients are calculated as a function of weight percent and wavelength using the refractive indices of Palmer and Williams (1975). An areaweighted average across latitude is conducted for all fields.

$5^{\circ} \mathrm{N}$, with a magnitude that is about double that of the $10 \mathrm{Tg}$ geoengineering case. Sulfate mass burden peaks at $8.5 \mathrm{Tg} \mathrm{S}$ about 5 months after the eruption, which is about $40 \%$ higher than $10 \mathrm{Tg}$ geoengineering. Our model is within the error bars of Pinatubo observations of peak magnitude and timing for AOD (Ansmann et al., 1996) and effective radius (Bauman et al., 2003) in the Northern Hemisphere. For purposes of a fair comparison to geoengineering simulations and to be similar to the approach of Heckendorn et al. (2009), we compare a 1-year average for the year immediately following the eruption, to the annual average of year 5 of the geoengineering simulations. Comparing the simulated Pinatubo eruption to $10 \mathrm{Tg}$ geoengineering, peak AOD is about $17 \%$ higher at $525 \mathrm{~nm}$ and $14 \%$ higher at $1024 \mathrm{~nm}$ despite similar $\mathrm{SO}_{2}$ injections (Fig. 2). While these differences might suggest that continuous injection of $\mathrm{SO}_{2}$ is slightly less effective than a single burst into a clean atmosphere, the Pinatubo injection was placed over a wider altitude and latitude range, but a narrower longitude range than the geoengineering case (Table 1). As we discuss below these spatial differences in injection can be very important to the resulting mass in the stratosphere.

Finally, AOD (Fig. 2) and sulfate column mass (Fig. 3) are about three times higher in the Northern Hemisphere than the Southern Hemisphere. Some of this increase is attributed to more surface sulfur sources in the Northern Hemisphere industrial latitudes as shown for the unperturbed case in Fig. 2; however there appears to be an additional contribution that could be due to an asymmetry in the location of the
Brewer-Dobson circulation about the equator in the WACCM model. This distribution should be investigated in more detail to better understand if equatorial injections for geoengineering may induce a hemispherically asymmetric forcing on the climate. Our model does not include a quasi-biennial oscillation (QBO) in tropical winds, or radiative heating from sulfate aerosols, both of which could influence the dynamics that partition sulfate between the hemispheres (Bauman et al., 2003). Indeed, our Pinatubo simulation also has higher AOD in the Northern Hemisphere than the Southern Hemisphere, but this is not supported by observations that show a more symmetrical AOD (Minnis et al., 1993, Stenchikov et al., 1998). In addition to the lack of QBO in our model, our model does not include the 1991 Cerro Hudson eruption in Chile, which was found to contribute to higher AOD in the Southern Hemisphere (Pitts and Thomason, 1993). A more detailed analysis of our simulation of Mount Pinatubo has been completed (English et al., 2012).

Analysis of size distributions in three different regions of the stratosphere (Fig. 5) illustrates how particle size evolves with changing injection rates. At higher injection rates, the peak particle size gets larger. The particle size grows even larger at the lowest levels of the stratosphere $(90 \mathrm{hPa}$ compared to $39 \mathrm{hPa}$ ), probably because of sedimentation of the largest particles. At $90 \mathrm{hPa}$, there is a size mode for geoengineering scenarios not present in the unperturbed atmosphere that increases in size from about $1 \mu \mathrm{m}$ radius for the $1 \mathrm{Tg}$ injection to about $1.5 \mu \mathrm{m}$ for the $10 \mathrm{Tg}$ injection. This trend was also found by Heckendorn et al., where the peak size at $90 \mathrm{hPa}$ was found to grow from about 0.6 to $1.0 \mu \mathrm{m}$. For the $5 \mathrm{Tg}$ injection, our model predicts effective radius in the center of the sulfate layer $(50 \mathrm{hPa}$ at the equator) to be 0.47 microns, compared to 0.6 microns for Heckendorn et al. (2009), and 0.4 microns for Neiemeier et al. (2010). Our model includes the coagulation correction for Van der Waal's forces (Chan and Mozurkevich, 2005), but we have found this increases the effective radius by less than $10 \%$ for Pinatubo. Generally the geoengineering cases have a broader size distribution than the Pinatubo case, rather than a different mode. This increase in the number of large particles with increasing injection rate occurs because the largest particles continue to see additional vapor for condensational growth. The differences in particle size by number correspond to even larger differences in particle size by surface area (Fig. 5). Clearly with greater mass there is also greater particle surface area, suggesting that ozone loss should increase, as has been calculated previously for geoengineering (Heckendorn et al., 2009; Tilmes et al., 2009) as well as observed after the eruption of Mount Pinatubo (Prather, 1992). The differences in the typical particle size are further amplified when comparing volume size distributions, suggesting that the higher injection scenarios have a higher proportion of sulfate mass in the largest sizes, which fall out of the atmosphere more rapidly. Larger particles are also less effective at scattering incoming solar radiation as the radius further deviates 

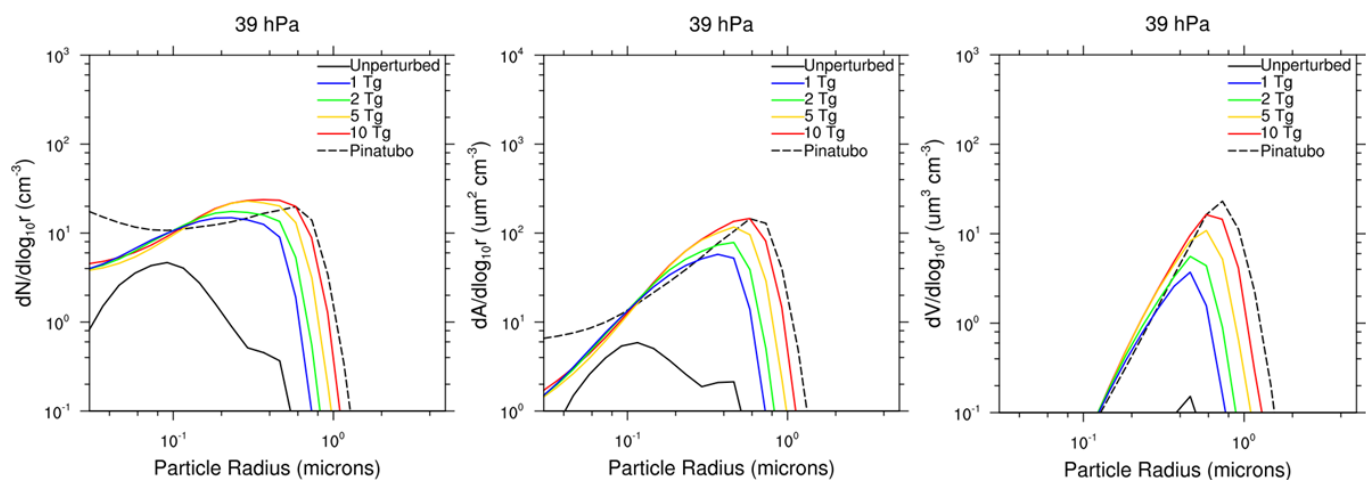

$55 \mathrm{hPa}$
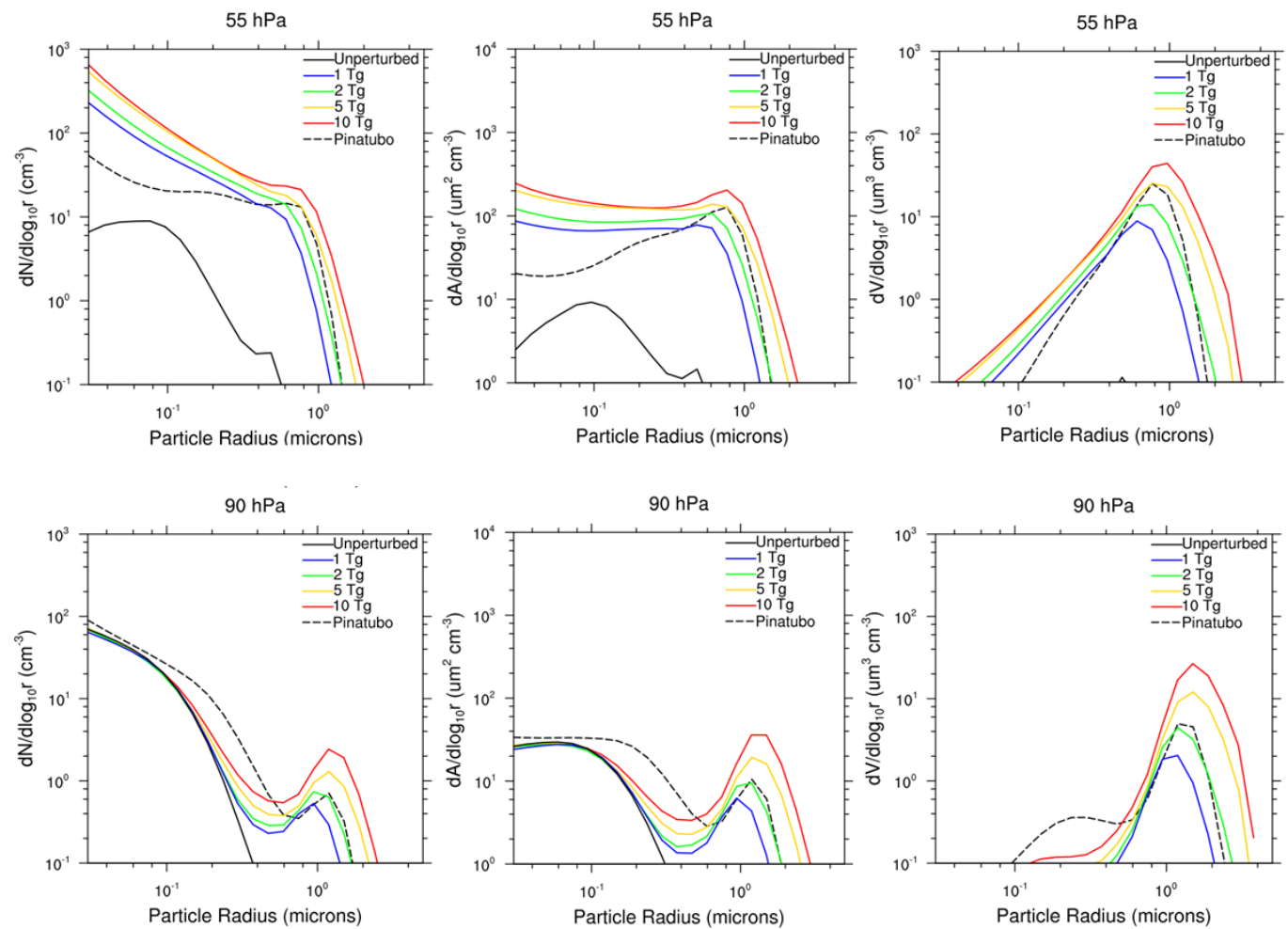

Fig. 5. Annual zonal average of sulfate aerosol number, surface area, and volume size distribution for each $\mathrm{SO}_{2}$ injection scenario at the equator and 39,55 , and $90 \mathrm{hPa}$.

from the optimum mass scattering radius near $150 \mathrm{~nm}$. Our results reinforce the original conclusion postulated by Pinto et al. (1989) as well as recent microphysical simulations (Heckendorn et al., 2009; Niemeier et al., 2010; Hommel and Graf, 2011) that there may be an upper limit to the radiative forcing that can be obtained with sulfate aerosols.

\subsection{Injection region}

We now compare the efficacy of injection region for various $10 \mathrm{Tg} \mathrm{S}$ injection scenarios. Injecting $\mathrm{SO}_{2}$ into a broader latitude and slightly higher altitude region $\left(32^{\circ} \mathrm{N}-32^{\circ} \mathrm{S}\right.$ and $19.9-24.6 \mathrm{~km}$ ) produces about a $60 \%$ higher mass burden than the equivalent $\mathrm{SO}_{2}$ injection in a narrow region $(10.1 \mathrm{Tg}$ versus $6.3 \mathrm{Tg}$ ) (Fig. 6). Injecting a lognormal distribution of $\mathrm{SO}_{4}^{2-}$ particles in a broad region produces about $40 \%$ higher mass burden than the equivalent injection of $\mathrm{SO}_{4}^{2-}$ particles in a narrow region $(13.8 \mathrm{Tg}$ versus $9.6 \mathrm{Tg}$ ). Likewise, stratospheric aerosol lifetime increases for broad injections by about $80 \%$ for $\mathrm{SO}_{2}$ injection and $50 \%$ for $\mathrm{SO}_{4}^{2-}$ particle injection relative to injections in narrow latitudinal bands (Fig. 6). While part of the increase in burden is due to the slightly higher injection altitude, burden is improved for two other reasons as well: First, particle growth by $\mathrm{H}_{2} \mathrm{SO}_{4}$ condensation is reduced because $\mathrm{H}_{2} \mathrm{SO}_{4}$ vapor is more dilute, and second, coagulation is reduced because aerosol concentration is also more dilute. The benefit of a larger injection region is less for $\mathrm{SO}_{4}^{2-}$ particle injection because this scenario is generally influenced by concentration of aerosol 

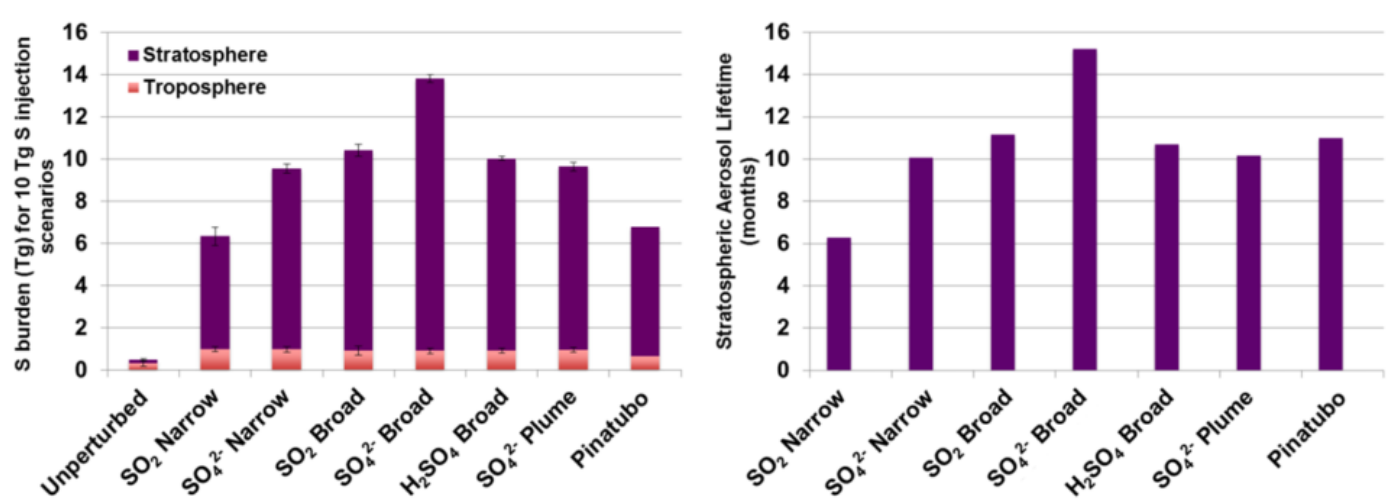

Fig. 6. Burdens and stratospheric lifetimes for various $10 \mathrm{Tg}$ injection scenarios. (left panel) Aerosol burden (Tg S) in the stratosphere and troposphere for various $10 \mathrm{Tg} \mathrm{S}$ injection scenarios. The sum is equivalent to whole atmosphere burden, since the burden above the stratopause was calculated to be less than $1 \mathrm{e}^{-6} \mathrm{Tg}$. Shown are averages and standard deviations across 360 daily averages for the 5 th simulation year for each simulation except Pinatubo. Pinatubo is calculated by averaging across one year immediately following the eruption. See text for method of identifying tropopause. (right panel) Stratospheric aerosol lifetime for various $10 \mathrm{Tg} \mathrm{S}$ injection scenarios. All lifetimes are calculated by dividing aerosol burden by mass injection rate, except Pinatubo, which is calculated by the elapsed time between the month of peak burden and the month of $\mathrm{e}^{-1}$ burden.

only, and not $\mathrm{H}_{2} \mathrm{SO}_{4}$. The impacts of these processes that result from changes in injection region are illustrated when looking at equatorial size distributions at three different levels of the stratosphere (Fig. 7). Injecting $\mathrm{SO}_{2}$ or $\mathrm{SO}_{4}^{2-}$ particles into a narrow region (green and blue dotted lines) generally results in a broader size distribution than injections into a broad region (green and blue solid lines). The distributions become especially wide with $\mathrm{SO}_{2}$ gas due to the availability of $\mathrm{H}_{2} \mathrm{SO}_{4}$ gas for growth in addition to $\mathrm{SO}_{4}^{2-}$ particles for coagulation.

The trends for area and volume distributions are comparable to trends with number. The differences are most noteworthy near the injection level $(55 \mathrm{hPa})$ and become muted at higher or lower levels. Sulfate effective radius (Fig. 8) is also generally larger across most latitudes and levels for the narrow injection simulations.

The combination of increased burden and reduced effective radius for broad injections results in higher AOD in most regions except near the equator, where the narrow injections have a higher injection rate (Fig. 9). It is particularly interesting that the Pinatubo simulation produces lower AOD than all but one of the $10 \mathrm{Tg}$ geoengineering cases. Generally this difference reflects the confined injection region for Pinatubo relative to the other cases. The differences in AOD are driven mainly by differences in sulfate column mass (Fig. 10), although a smaller effective radius for the broad injections (Fig. 10) is a factor. The effective radius for $\mathrm{SO}_{2}$ injections is similar in most places except a narrow band near the equator. However, this is where the majority of the sulfate column mass is located, reducing the efficacy of a narrow injection. Overall, a broad injection can be considered an improvement over a narrow injection when comparing averages from $30^{\circ} \mathrm{S}$ to $30^{\circ} \mathrm{N}$ (Fig. 11). AOD for broad injections of $\mathrm{SO}_{2}$ gas and $\mathrm{SO}_{4}^{2-}$ particles is about $20-60 \%$ higher at both $525 \mathrm{~nm}$ and
$1024 \mathrm{~nm}$, with $\mathrm{SO}_{2}$ injections showing a larger benefit from a broad injection. However, due to the spatial differences in AOD (Fig. 9), different climatic outcomes may result from a narrow versus a broad injection, and the potential impacts should be studied further.

When comparing a narrow $\mathrm{SO}_{4}^{2-}$ particle injection across all longitudes (" $\mathrm{SO}_{4}^{2-}$ narrow") to a narrow $\mathrm{SO}_{4}^{2-}$ particle injection across only 10 degrees longitude with the same total injection (" $\mathrm{SO}_{4}^{2-}$ plume"), the resulting aerosol burdens (Fig. 6), lifetime (Fig. 6), size distributions (Fig. 7), effective radii (Fig. 10), AOD (Fig. 9), column mass (Fig. 10), and averages in the tropics (Fig. 11) are all comparable. This suggests that the zonal winds distribute the aerosol particles around the world quickly enough to not impact microphysics.

\subsection{Injection species}

We now compare the efficacy of injecting three different sulfur species: $\mathrm{SO}_{2}$ gas, $\mathrm{H}_{2} \mathrm{SO}_{4}$ gas, and $\mathrm{SO}_{4}^{2-}$ particles. Pierce et al. (2010) suggested that injecting $\mathrm{H}_{2} \mathrm{SO}_{4}$ gas that is instantly well-mixed throughout the gridbox instead of $\mathrm{SO}_{2}$ would result in a larger sulfate mass abundance for a given injection rate. We find, on the other hand, that injecting $\mathrm{H}_{2} \mathrm{SO}_{4}$ gas does not produce any discernable benefit over $\mathrm{SO}_{2}$ injection. Aerosol burden (Fig. 6), stratospheric lifetime (Fig. 6), size distributions (Fig. 7) AOD (Fig. 9), column mass (Fig. 10), and effective radius (Fig. 10) are all similar for the two scenarios. However, Pierce et al. (2010) did not directly inject $\mathrm{H}_{2} \mathrm{SO}_{4}$ into their global microphysical model. Instead, they injected $\mathrm{H}_{2} \mathrm{SO}_{4}$ into a plume model, and let the plume evolve until all of the gas had been converted into particles, and the particle concentration had been reduced to ambient values. They then put the plume particles into the global microphysical model, assuming a range of 

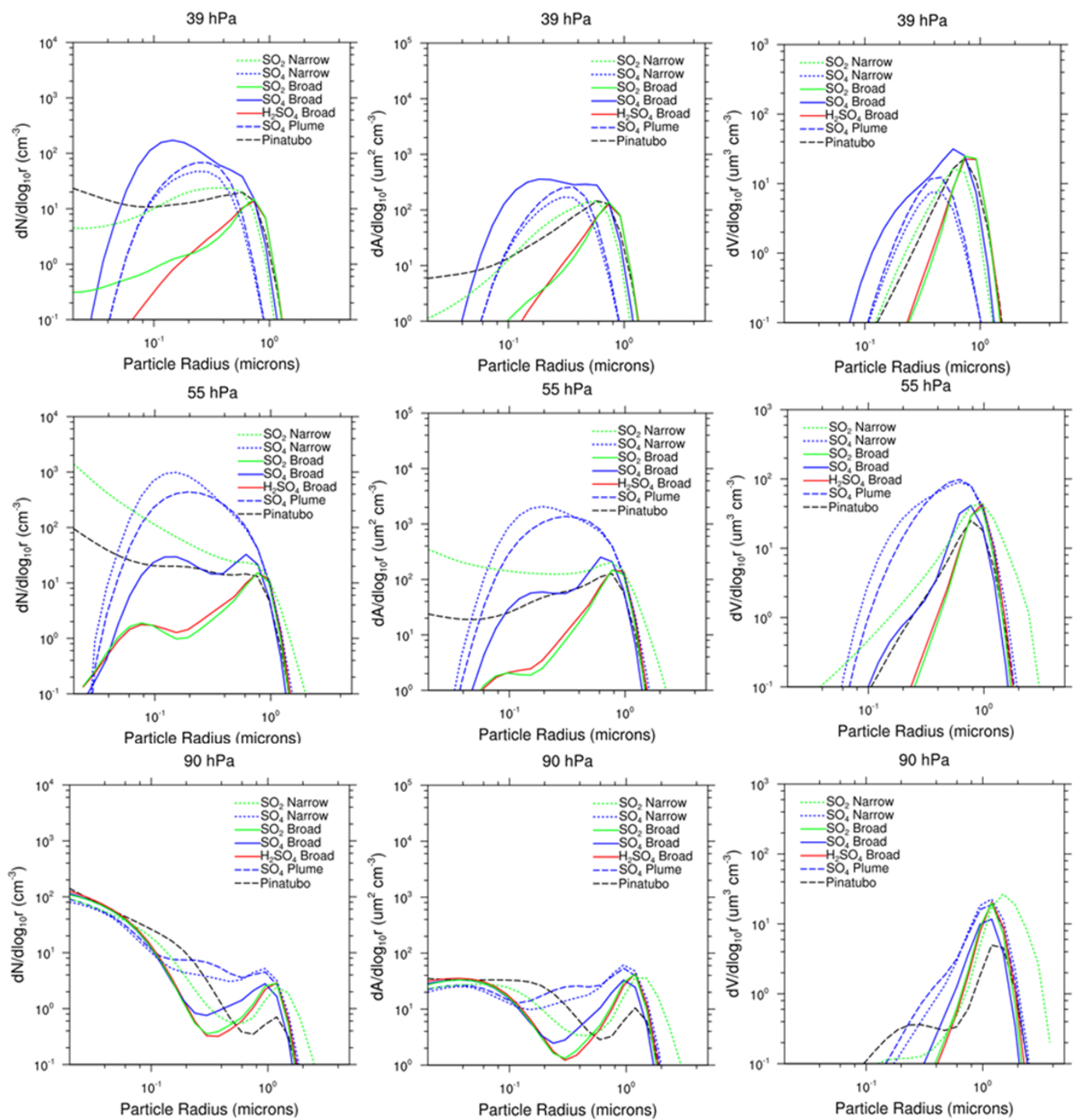

Fig. 7. Annual zonal average of aerosol number, surface area, and volume size distribution for each $10 \mathrm{Tg} \mathrm{S}$ geoengineering scenario at the equator and 39,55 , and $90 \mathrm{hPa}$.

injected particle sizes. This approach yielded higher burdens, by minimizing the exposure of the pre-existing aerosol particles to $\mathrm{H}_{2} \mathrm{SO}_{4}$ gas. It is likely that their plume model is responsible for the difference between results. What is unclear is the uncertainty in their assumptions made with their approach before they handed of a specified particle size distribution to the GCM. Pierce et al. discuss some of the assumptions with their approach in their Supplement, and acknowledge that the resulting particle size distribution could vary in peak size and width depending on the assumptions. However, it would be difficult to quantify the uncertainty in some of their assumptions. For instance, coagulation is nonlinear so it is critical that plumes be allowed to interact with other plumes that have been produced previously. In order to inject $10 \mathrm{Tg} \mathrm{S} \mathrm{yr}^{-1} \mathrm{H}_{2} \mathrm{SO}_{4}$, assuming 1 ton of $\mathrm{H}_{2} \mathrm{SO}_{4}$ per aircraft (which is a typical payload for the handful of aircraft actually able to fly at these altitudes today), would require about 80000 aircraft flights per day. It is most likely these flights would be concentrated in a few areas of the Earth to make the logistics of operating the aircraft more economical. Hence plume interaction would almost certainly occur. Other details of the plume model, such as turbulence, may be important to the particle sizes that exit the plume, and should be validated in field studies.

We are not able to address these many complexities involving sub-grid scale injection, which would require a global model with many subgrid-scale embedded aircraft plumes. However, we performed some illustrative simulations. Figure 6 shows that injecting $\mathrm{SO}_{4}^{2-}$ particles with a lognormal distribution of width 1.5 and peak radius of $100 \mathrm{~nm}$ produces 

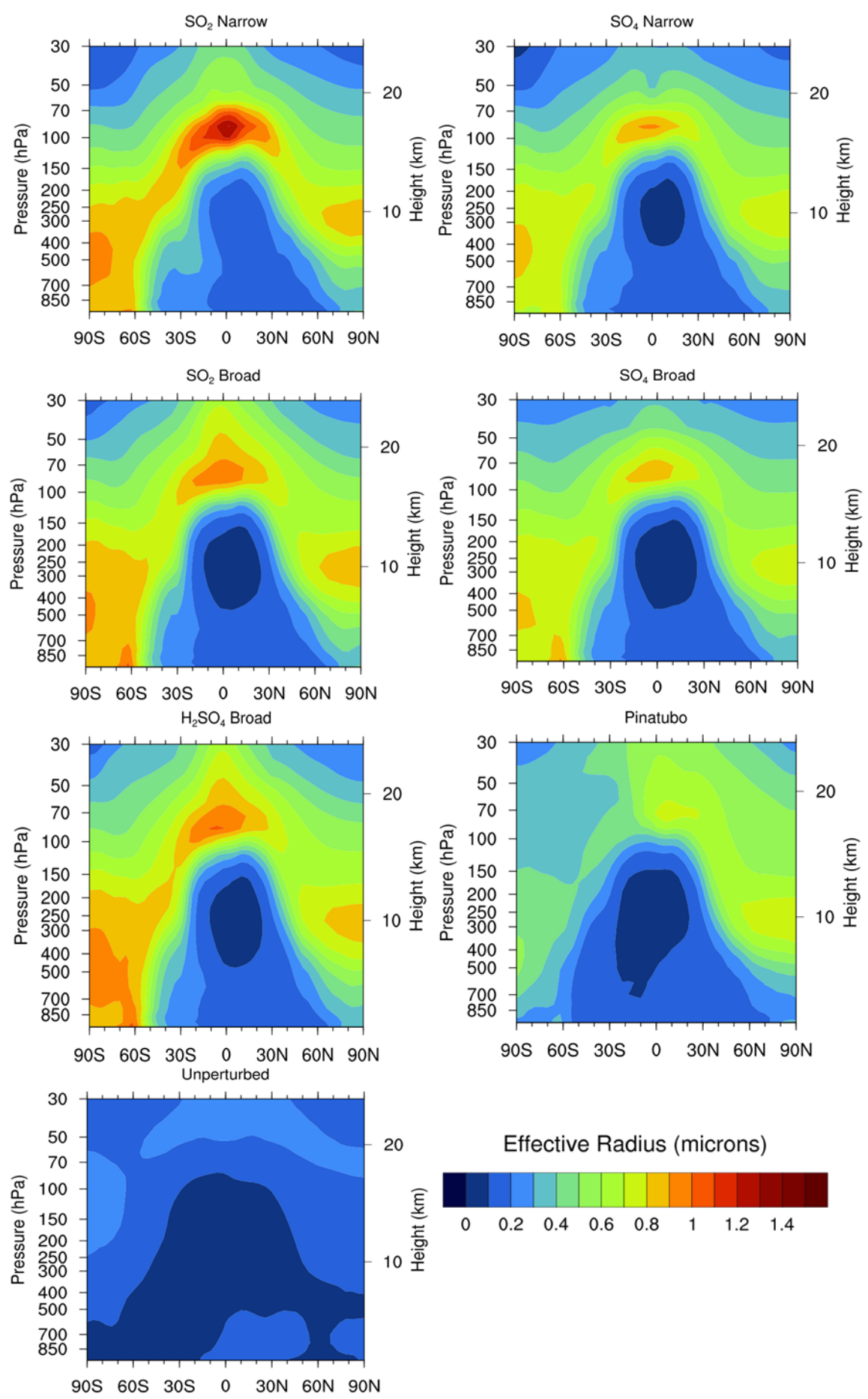

$20 \quad$ Effective Radius (microns)

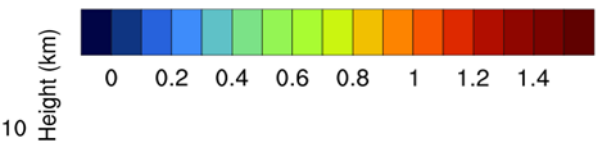

Fig. 8. Hydrated sulfate effective radius for each of the various $10 \mathrm{TgS}$ injection schemes; annual and zonal average as a function of atmospheric pressure and latitude (average of year 5). Pinatubo simulation is an average of the first year after the simulated eruption.

$51 \%$ higher mass burdens than $\mathrm{SO}_{2}$ injection in a narrow region and $37 \%$ higher burdens than in a broad region. Higher mass burden is achieved because coagulation is inherently slower at delivering mass to a growing particle than growth from the gas phase. Hence the particles remain smaller if particles are injected instead of a gas, and therefore do not fall out of the stratosphere as fast. In the limit when particles are smaller than the mean free path, the ratio of the coagulation growth rate to the condensational growth rate is approximately equal to the ratio of the thermal velocity of the 

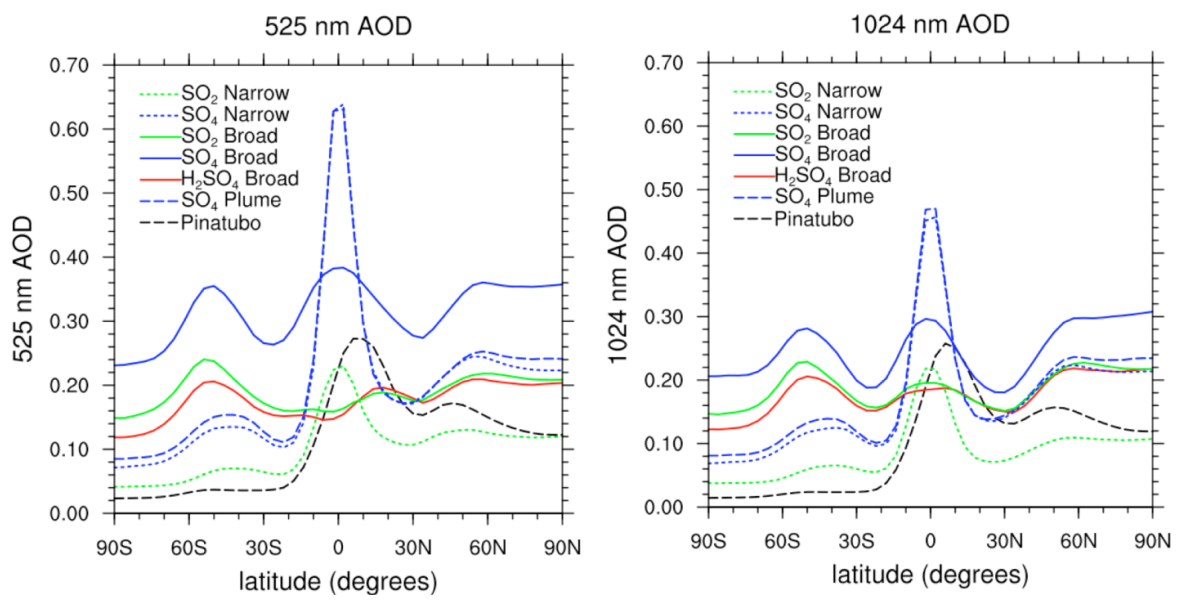

Fig. 9. Annual zonal average of AOD at 525 and $1024 \mathrm{~nm}$ wavelength for each of the $10 \mathrm{Tg}$ S geoengineering simulations (average of year 5) and for Pinatubo (average of the 1-year period starting immediately after the 15 June eruption). Extinction coefficients are calculated as a function of weight percent and wavelength using the refractive indices of Palmer and Williams (1975).
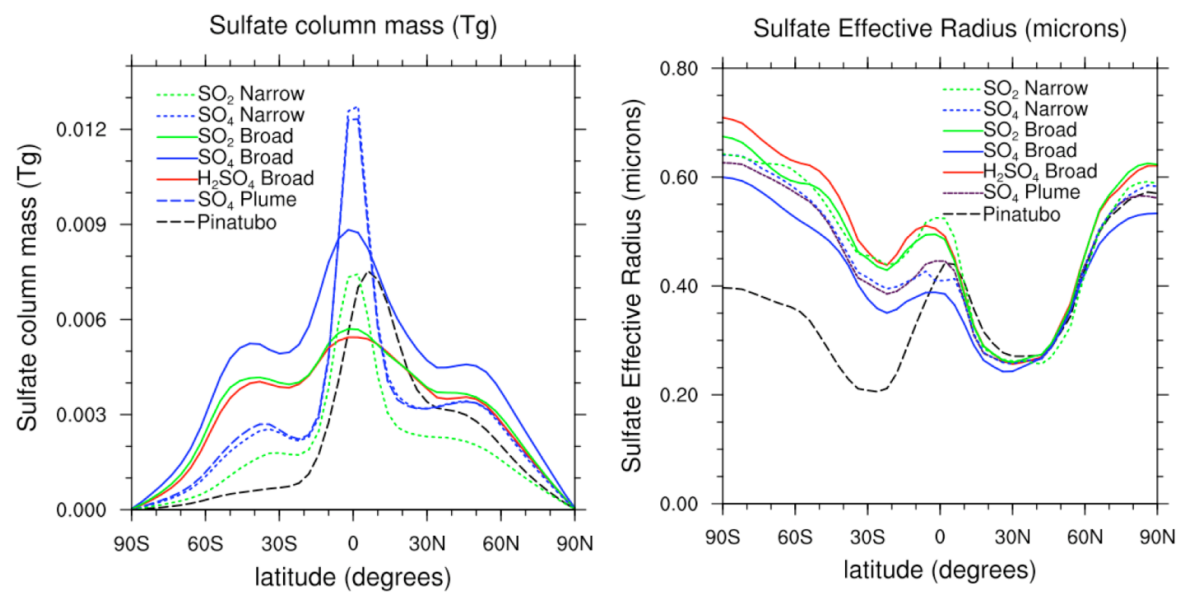

Fig. 10. Annual zonal average of sulfate column mass ( $\mathrm{Tg}$ ) and hydrated sulfate effective radius ( $\mu \mathrm{m})$ for each of the $10 \mathrm{Tg} \mathrm{S}$ Geoengineering simulations (average of year 5) and for Pinatubo (average of the 1-year period starting immediately after the June 15 eruption). Column Mass is reported per grid box ( $4^{\circ}$ latitude by $5^{\circ}$ longitude). Effective radius is a column average weighted by the aerosol surface area in each grid box vertically to apply a fair weighting to grid boxes with more surface area.

particle to the thermal velocity of the colliding aerosol, or equivalently the square root of the ratio of their masses. This effect is supported by comparisons of effective radius. For $\mathrm{SO}_{4}^{2-}$ particle injection, global zonal-average effective radius (Fig. 8) peaks at roughly $0.9 \mu \mathrm{m}$ for a narrow region and $0.8 \mu \mathrm{m}$ for a broad region, which is $37 \%$ and $11 \%$ smaller, respectively, than that from an $\mathrm{SO}_{2}$ injection. Comparing surface area-weighted average of effective radius as a function of latitude (Fig. 10), effective radius for a $\mathrm{SO}_{4}^{2-}$ particle injection is about $10 \%$ lower than for $\mathrm{SO}_{2}$ injection at most latitudes. Finally, a comparison of average effective radius between $30^{\circ} \mathrm{S}$ and $30^{\circ} \mathrm{N}$ (Fig. 11) suggests effective radius for an $\mathrm{SO}_{4}^{2-}$ particle injection is about $15 \%$ smaller. Comparison of size distributions (Fig. 7) also illustrate the narrower distributions attained with a $\mathrm{SO}_{4}^{2-}$ particle injection instead of $\mathrm{SO}_{2}$ gas. The advantage of higher burden and smaller particles is illustrated when comparing AOD (Fig. 9, blue lines versus green lines). In both narrow and broad injection regions, $\mathrm{AOD}$ from $\mathrm{SO}_{4}^{2-}$ particle injection is more than twice that of $\mathrm{SO}_{2}$ injection at $525 \mathrm{~nm}$ and nearly twice that of $\mathrm{SO}_{2}$ at $1024 \mathrm{~nm}$. Higher AOD for $\mathrm{SO}_{4}^{2-}$ particle injections comes from both higher sulfate column mass (Fig. 10) and smaller effective radius (Fig. 10).

The primary advantage of injecting $\mathrm{SO}_{4}^{2-}$ particles is to control the particle size distribution, as noted by Pierce et al. (2010). However, it is unlikely that the size distribution remains as narrow as assumed in their plume model, an uncertainty that they acknowledge is possible. Given that the 


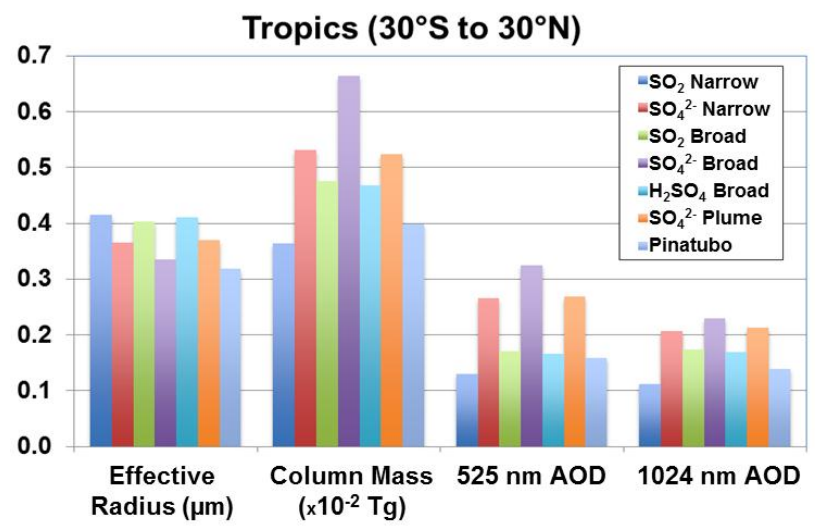

Fig. 11. Hydrated sulfate effective radius $(\mu \mathrm{m})$, sulfate column mass $\left(10^{-2} \mathrm{Tg} /\right.$ grid box $)$, and sulfate AOD at $525 \mathrm{~nm}$ and $1024 \mathrm{~nm}$ in the tropics $\left(30^{\circ} \mathrm{S}\right.$ to $\left.30^{\circ} \mathrm{N}\right)$ for each of the $10 \mathrm{Tg} \mathrm{S}$ Geoengineering scenarios. Effective radius is a column average weighted by the aerosol surface area in each grid box vertically to apply a fair weighting to grid boxes with more surface area. Extinction coefficients are calculated as a function of weight percent and wavelength using the refractive indices of Palmer and Williams (1975). An area-weighted average across latitude is conducted for all fields.

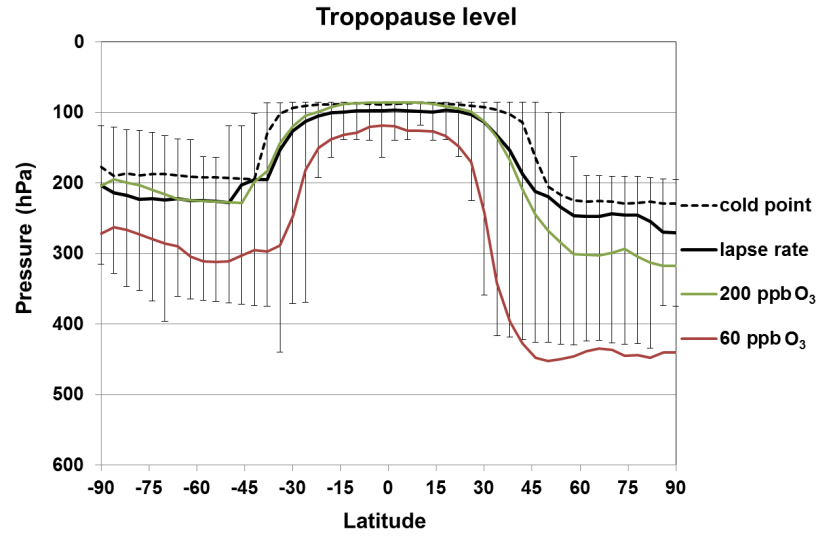

Fig. 12. Simulated tropopause level (hPa) as a function of latitude for varying identification methods, based on an annual zonal average for the unperturbed simulation. The lapse rate method (described in the text) was employed for this work. The bars show minimum and maximum tropopause levels at each latitude across all longitudes and 360 daily averages for the 5th simulation year.

availability of very small particles for coagulation onto larger particles is a controlling factor for peak size, it is critical to correctly identify the size distribution. Since our results for $\mathrm{H}_{2} \mathrm{SO}_{4}$ injection are virtually identical to that for $\mathrm{SO}_{2}$ injection, it is clear that the Pierce et al. plume model is the critical factor in their results, rather than injecting $\mathrm{H}_{2} \mathrm{SO}_{4}$ instead of $\mathrm{SO}_{2}$. It would be valuable to validate these assumptions with size distributions observed in an actual plume.

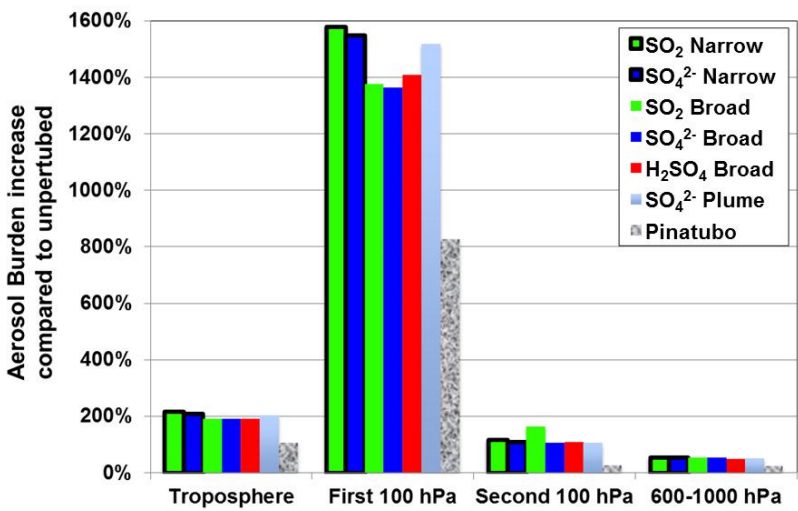

Fig. 13. Percent increase in sulfate mass burden in different regions for each $10 \mathrm{TgS}$ geoengineering simulations compared to the unperturbed case. "First $100 \mathrm{hPa}$ " represents the region spanning from the tropopause to $100 \mathrm{hPa}$ below the tropopause. "Second $100 \mathrm{hPa}$ " spans $100 \mathrm{hPa}$ below the tropopause to $200 \mathrm{hPa}$ below the tropopause. "600-1000 hPa" spans from $600 \mathrm{mb}$ to the surface. See text for method of identifying tropopause.

\section{Tropospheric burdens}

Next, we investigate perturbations to tropospheric aerosol resulting from stratospheric sulfur injection. In order to accurately quantify perturbations to tropospheric aerosol, the height of the tropopause must be adequately represented. This is a difficult task. The constantly changing temperature profile of the atmosphere argues against using an average tropopause height. If the tropopause is defined based on cold-point temperature, the tropopause can be unrealistically high when there is an extended region of stable temperatures that sometimes occurs in high latitudes. Our model sometimes predicts cold-point tropopause in southern hemisphere high latitudes as high as $80 \mathrm{hPa}$. If the tropopause is based on ozone concentration, the method becomes inadequate during the Antarctic spring ozone hole. Additionally, the ozone concentration separating tropospheric from stratospheric air can vary from 50 to $380 \mathrm{ppb}$ (Zahn et al., 1999; Pan et al., 2004). A third technique to identify tropopause is based on a minimum lapse rate. We find that using a modified version of the World Meteorological Organization definition (WMO, 1957) produces a realistic tropopause location that can handle the nuances of uncommon temperature profiles that sometimes occur in our simulated daily average temperatures. We identify the tropopause to be the lowest level at which the lapse rate is closer to zero than $+4 \mathrm{~K} \mathrm{~km}^{-1}$ at that level and the level above it. If the lapse rate at the level above the current level is $-2 \mathrm{~K} \mathrm{~km}^{-1}$ or less, the current level is flagged as the tropopause regardless of whether the current level lapse rate is less than $+4 \mathrm{~K} \mathrm{~km}^{-1}$. The search begins above the boundary layer to avoid designation of boundary layer inversions as the tropopause. Tropopause levels were constrained to be between the levels 85 to $433 \mathrm{hPa}$. A comparison of identified 


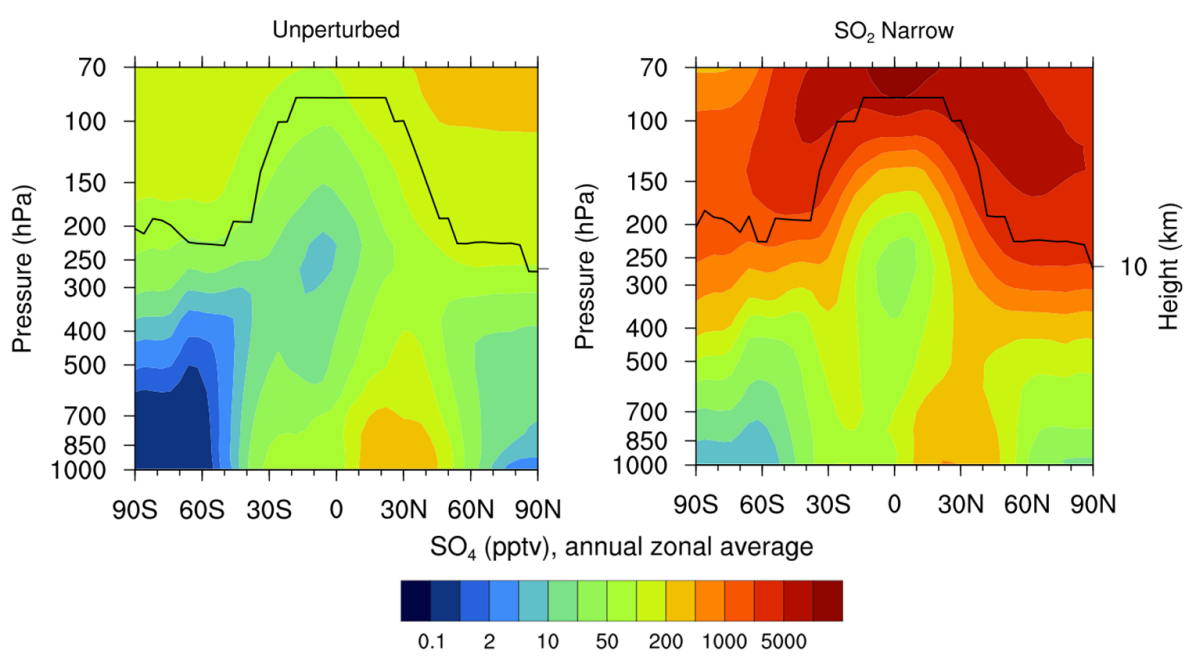

Fig. 14. Tropospheric sulfate aerosol burden (pptv) for the unperturbed case and the " $\mathrm{SO}_{2}$ narrow" geoengineering simulation; annual and zonal average as a function of atmospheric pressure and latitude. The annual zonal average tropopause location is included (black line). See text for method of identifying tropopause.

tropopause locations for the annual zonal average of the unperturbed simulation is provided in Fig. 12. Our modified lapse rate definition identifies an average tropopause of about $100 \mathrm{hPa}$ in the tropics and $250 \mathrm{hPa}$ at high latitudes. This approach yields an average tropopause at about the same location as a method searching for $200 \mathrm{ppb}$ ozone concentration. This method identifies a tropopause that is higher than the $60 \mathrm{ppb}$ ozone method, and lower than the cold-point method. An analysis of 360 daily averages at each of the 72 longitudes finds that the designated tropopause location ranges from 86 to $160 \mathrm{hPa}$ in the tropics, 120 to $433 \mathrm{hPa}$ at southern hemisphere high latitudes, and 190 to $433 \mathrm{hPa}$ at northern hemispheric high latitudes. This range of daily tropopause locations approximately spans from the $60 \mathrm{ppb}$ ozone average location at the low end to the cold point average tropopause location at the high end.

Based on our designation of tropopause location, we find significant perturbations to tropospheric aerosol from stratospheric geoengineering. When comparing the narrow-region $\mathrm{SO}_{2}$ injection scenarios, sulfate burden in the troposphere increases as the injection rate increases (Fig. 1, green solid line), with the tropospheric burden for the $10 \mathrm{Tg}$ injection nearly triple that of the unperturbed case. This increase is consistent with tropospheric burdens found in other microphysical studies (Debra Weisenstein, private communication). The majority of this increase occurs in the first $100 \mathrm{hPa}$ below the tropopause. In Fig. 1, the slope of the 600$1000 \mathrm{hPa}$ line is near zero, suggesting that perturbations of sulfate near the surface from geoengineering are insignificant compared to traditional sulfur sources (which are represented by the zero injection point in Fig. 1). A significant portion of the atmospheric burden for all of the $10 \mathrm{Tg}$ geoengineering scenarios is in the troposphere (Fig. 6, pink columns).
Increases in specific regions of the troposphere are provided in Fig. 13. Total tropospheric burdens increase by about $200 \%$ for all of the $10 \mathrm{Tg}$ scenarios, with the increases slightly less for the broad region injections than the narrow region injections. There is no significant difference in tropospheric burden increases between injections of $\mathrm{SO}_{2}$ gas, $\mathrm{H}_{2} \mathrm{SO}_{4}$ gas, or $\mathrm{SO}_{4}^{2-}$ particles. The vast majority of the tropospheric increases occur in the first $100 \mathrm{hPa}$ below the tropopause, where the burdens increase by a factor of about 15. Again, the narrow injections cause a larger perturbation. Tropospheric burdens in the next $100 \mathrm{hPa}$ down from the tropopause are doubled, while burdens near the surface increase by about $50 \%$. While wet deposition is the primary tropospheric sink of sulfate aerosols (Textor et al., 2006), the lack of dry deposition in our model may introduce some error in surface perturbations.

Comparison of sulfate volumetric mixing ratio between the unperturbed case and the $\mathrm{SO}_{2}$ narrow $10 \mathrm{Tg}$ injection (Fig. 14) suggests increased burdens across much of the upper troposphere and high latitudes. Sulfate concentrations near the equator at the $120 \mathrm{hPa}$ level increase 100 -fold, from about 50 pptv to about 5 ppbv. Similarly, sulfate concentrations near the South Pole and $400 \mathrm{hPa}$ increase from about 3 pptv to $300 \mathrm{pptv}$. Increases in sulfate burden relative to ambient concentrations for each of the $10 \mathrm{Tg}$ geoengineering scenarios are illustrated in Fig. 15. Sulfate increases are largest in the clean high latitude regions for all of the injection scenarios, as well as the upper troposphere at all latitudes, where burdens increase by about a factor of 100 . All of these increases are about double that calculated for the year after the Pinatubo eruption (Figs. 6, 13, 15) due to the continuous injection, larger particle size, and faster falling velocities for the geoengineering cases, as well as 

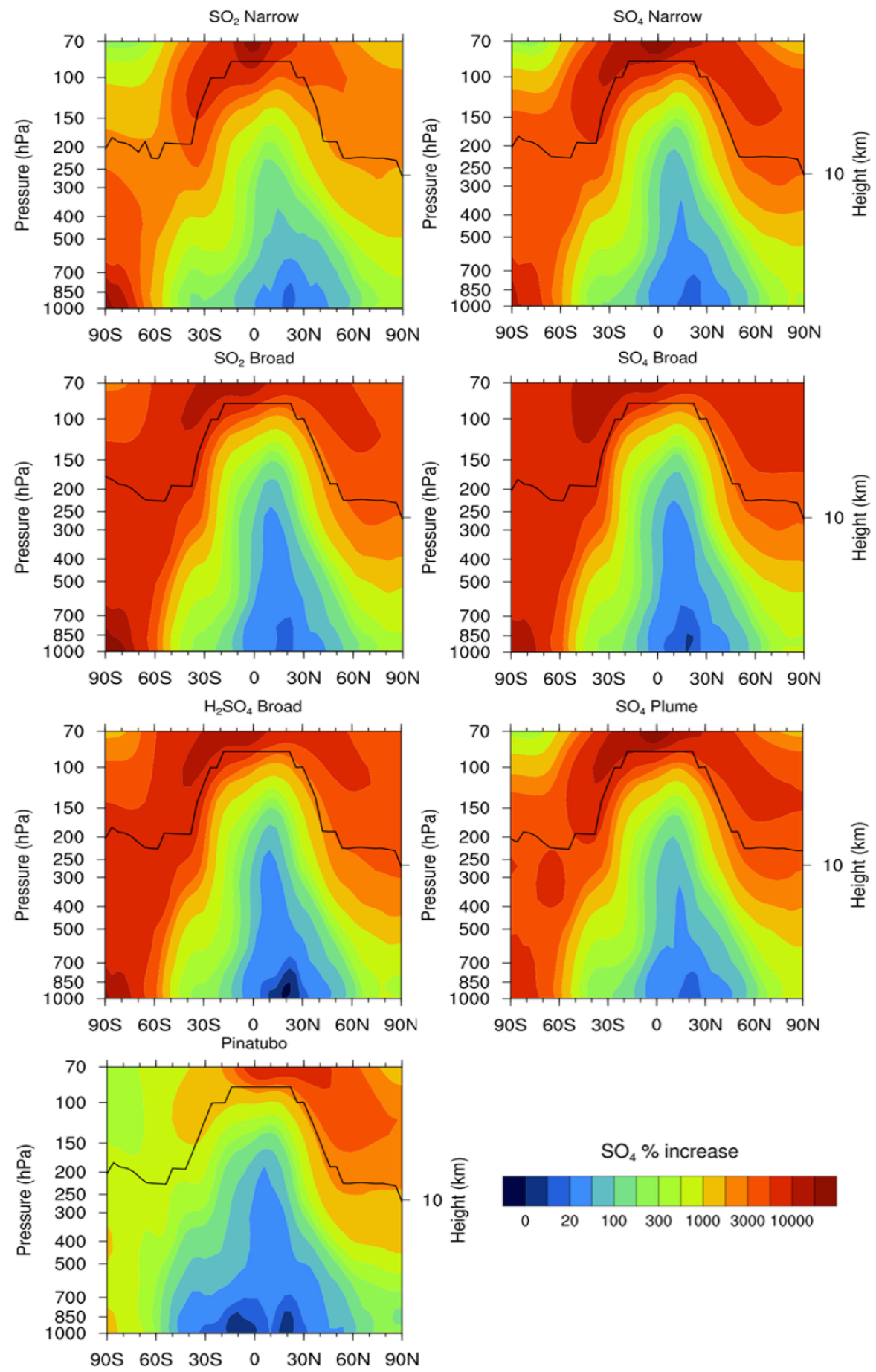

Fig. 15. Percent increase in tropospheric sulfate aerosol burden for each $10 \mathrm{Tg} \mathrm{S}$ geoengineering simulation compared to the unperturbed case; annual and zonal average as a function of atmospheric pressure and latitude (average of year 5). Pinatubo simulation is an average of the first year after the simulated eruption. The annual zonal average tropopause location is included (black lines). See text for method of identifying tropopause.

their accumulated burden from previous years. Our model does not include dimethyl sulfide (DMS) emissions, which contributes about $20 \%$ of surface sulfur emissions globally (Haywood and Boucher, 2000), or in-cloud production of sulfate. Our unperturbed simulation predicts a global atmospheric sulfate burden of $0.49 \mathrm{TgS}$ which is outside the range of IPCC simulations ( 0.55 to $1.1 \mathrm{TgS}$ ) that include DMS and in-cloud production of sulfate (Forster et al., 2007). 

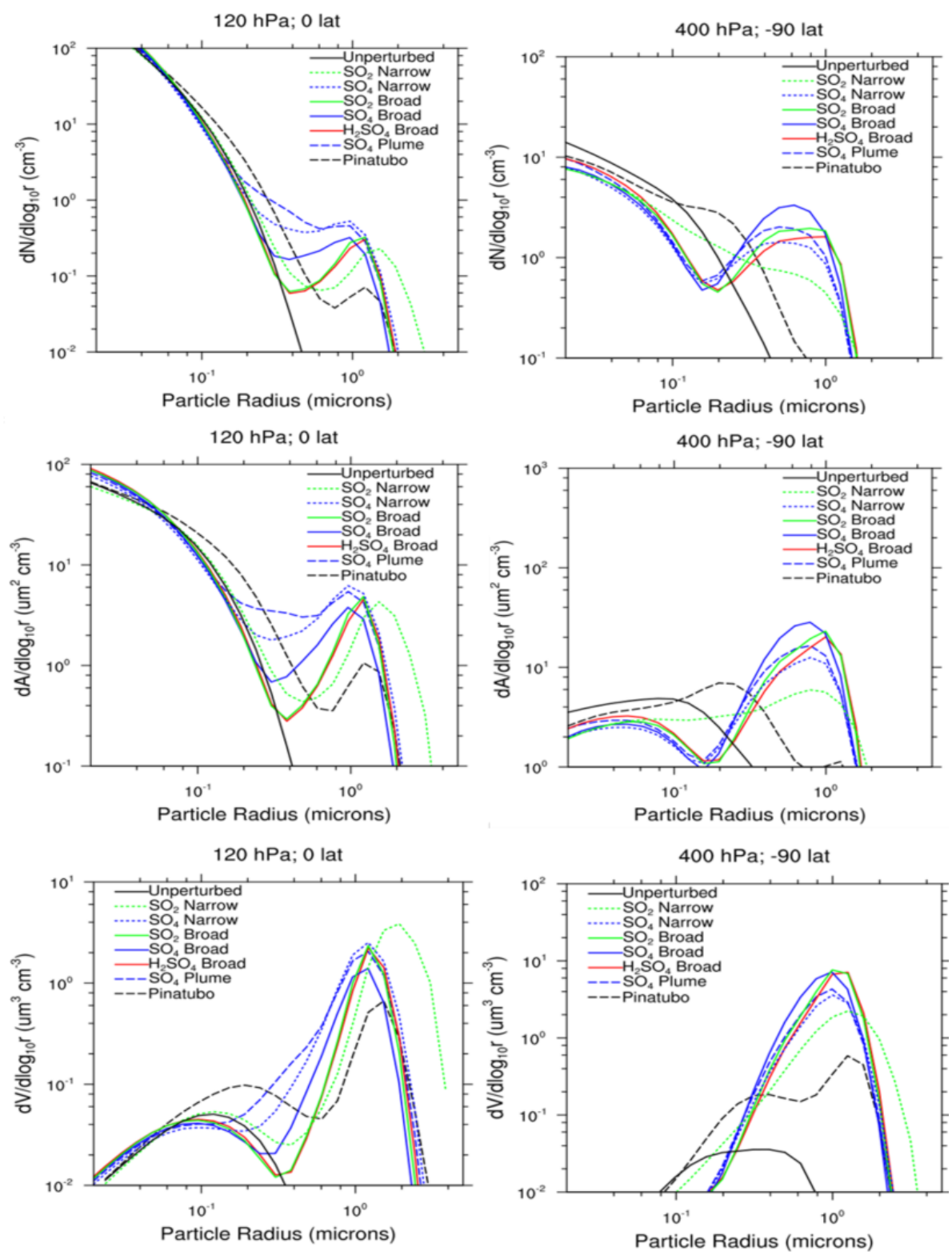

Fig. 16. Annual zonal average of aerosol number, surface area, and volume distribution for each $10 \mathrm{Tg} \mathrm{S}$ geoengineering simulation in the tropical upper troposphere (the equator and $120 \mathrm{hPa}$; left column), and the southern high latitude upper troposphere $\left(90^{\circ} \mathrm{S}\right.$ and $400 \mathrm{hPa}$; right column).

Therefore, fractional increases of sulfate due to geoengineering in our model may be artificially high, particularly in the high latitude Southern Hemisphere where DMS emissions peak.

An assessment of aerosol number, surface area, and volume distributions in the upper troposphere (Fig. 16) reveals significant changes to aerosol properties for all $10 \mathrm{Tg}$ geoengineering simulations. In both the tropical upper troposphere (at the equator and $120 \mathrm{hPa}$ ) as well as the high latitude upper troposphere $\left(90^{\circ} \mathrm{S}\right.$ and $\left.400 \mathrm{hPa}\right)$, stratospheric geoengineering produces a size mode at approximately $1 \mu \mathrm{m}$ radius that is not present in the unperturbed simulation. Large increases to aerosol surface area and volume are predicted as well. As expected, the narrow tropical injection scenarios perturb the tropical upper troposphere more significantly while the broader injection scenarios perturb the high latitude upper troposphere more significantly. The Pinatubo simulation also predicts changes to upper tropospheric aerosol, but the perturbations are generally much smaller than those from geoengineering. Finally, despite high numbers of particles smaller than $300 \mathrm{~nm}$ predicted for all simulations in the tropical upper troposphere due to binary homogeneous 
nucleation of sulfuric acid and water in this region (English et al., 2011), geoengineering produces a new size mode.

This enhancement of tropospheric sulfate burdens could have implications for tropospheric cloud properties, radiative forcing, and tropospheric chemistry. After the eruption of Mt. Pinatubo, large aerosols were found in the upper troposphere (Sato et al., 1993; Stenchikov et al., 1998; Niemeier et al., 2009). Some observational analyses observed an increase in cirrus clouds and a decrease in low clouds (Minnis et al., 1993; Ackerman and Strabala, 1994), which could cause surface warming, offsetting some of the cooling induced by the stratospheric aerosols. However, other observational analyses have failed to find a connection between Pinatubo and cirrus (Luo et al., 1997). It is possible that El Niño contributed to the change in cirrus properties that year (Song et al., 1996), but other analyses suggest El Niño was insignificant compared to the effects of Mt. Pinatubo (Wang et al., 1995). Modeling sensitivity studies have found Pinatubo to perturb cirrus if a monomodal aerosol distribution is prescribed but not a bimodal distribution (Lohmann et al., 2003). Clearly this is an issue that needs more research in the context of geoengineering. Furthermore, our calculations suggest that geoengineering perturbs tropospheric aerosol more than Mount Pinatubo. If geoengineering with larger injection rates increases the thin cloud to thick cloud ratio further, while reaching a reflective cooling plateau in the stratosphere, the effectiveness of sulfate injections could be further limited. Finally, our simulations predict sulfate burdens in the lower atmosphere near the South Pole to increase by up to two orders of magnitude (Fig. 15), increasing the likelihood of acid deposition, which has been previously noted, though it was concluded that this increase is several orders of magnitude too small to cause ecological harm (Kravitz et al., 2009).

In addition to modifying cirrus, enhanced tropospheric particles could modify atmospheric chemistry by providing surfaces for heterogeneous reactions, or radiative heating rates. Sulfuric acid aerosols are known to heat the stratosphere after large volcanic eruptions, and could do the same in the tropopause region if high concentrations were maintained by persistent injections for geoengineering.

\section{Conclusions}

We have used a 3-D coupled microphysical sectional model to study the effect of sulfur injection magnitude, injection zone size, and injection species $\left(\mathrm{SO}_{2}, \mathrm{H}_{2} \mathrm{SO}_{4}\right.$, and $\mathrm{SO}_{4}^{2-}$ particles) on aerosol properties in the stratosphere and troposphere. We find that continuous $\mathrm{SO}_{2}$ injection in a narrow region centered at the equator has limited efficacy at higher injection rates, in agreement with Heckendorn et al. (2009) and others. We find that broadening the injection region to $32^{\circ} \mathrm{N}-32^{\circ} \mathrm{S}$ and $19.9-24.6 \mathrm{~km}$ increases the sulfate burden by approximately $50 \%$ for a $10 \mathrm{Tg} \mathrm{S} \mathrm{yr}^{-1}$ injection, and that injection of $\mathrm{SO}_{4}^{2-}$ particles instead of $\mathrm{SO}_{2}$ gas increases sul- fate burden by another $50 \%$, in agreement with Pierce et al. (2010). We also find that injection of $\mathrm{H}_{2} \mathrm{SO}_{4}$ gas does not increase burdens compared to $\mathrm{SO}_{2}$ injection, in contrast with Pierce et al. (2010). Clearly their plume model is the critical factor in their results. Although Pierce et al. conducted a sensitivity study using their plume model, they acknowledge that there remain uncertainties with particle size distribution. We suggest that considerably more research is needed on plumes to consider issues such as interactions between plumes, the particle size as a function of mass injected by single aircraft, and coagulation within plumes before they spread, among other topics. While previous studies have suggested geoengineering injections are less effective than volcanic ones in increasing sulfate mass burdens, we find the opposite is true for most of the cases we studied. The main reason is that volcanic injections are spatially confined, while most of the simulations we considered were for injections over broad regions. Hence, geographical distribution of the injection may be more important than the injection rate in general.

We also find significant perturbations to tropospheric aerosol burdens for all geoengineering simulations. Tropospheric burdens increase by a factor of two or three, with the majority of the increases occurring at all latitudes in the $100 \mathrm{hPa}$ thick layer just below the tropopause, as well as most of the troposphere at high latitudes. Aerosol size, surface area, and volume are all perturbed in the tropical upper troposphere as well as the high latitude upper troposphere, and at a much greater level than simulated for the eruption of Mount Pinatubo. These perturbations could impact cirrus clouds, and as a result, radiative forcing and geoengineering efficacy, and alter chemical reaction rates and radiative heating in the upper troposphere. More work needs to be done to clarify whether cloud properties are modified from changes in aerosol abundance or upper tropospheric heating.

These results highlight the unforeseen impacts that stratospheric geoengineering may entail. In addition to cirrus cloud modification and limited efficacy at higher injection rates, stratospheric sulfur injections may cause ozone destruction (Tilmes et al., 2009; Heckendorn et al., 2009), changes to the hydrological cycle (Trenberth and Dai, 2007), acid deposition at the poles (Kravitz et al., 2009), as well as consequences yet unknown. Geoengineering by solar radiation management also would not offset other adverse consequences of $\mathrm{CO}_{2}$ emissions such as ocean acidification. Although geoengineering is riddled with risks, costs, and uncertainties, humanity's current path of releasing greenhouse gases also creates risks, costs, and uncertainties. Therefore, geoengineering should receive further study to better constrain its risks, costs, and uncertainties, but not distract from efforts to quickly reduce $\mathrm{CO}_{2}$ and other greenhouse emissions. 
Acknowledgements. We thank Charles Bardeen for help coupling CARMA and CAM. We thank Debra Weisenstein for providing tropospheric burdens for comparison. We gratefully utilized the NCAR Command Language software to create some of our plots (Version 6.0.0, Boulder, Colorado: UCAR/NCAR/CISL/VETS. http://dx.doi.org/10.5065/D6WD3XH5). We thank Jeffrey Pierce and one anonymous reviewer for helpful suggestions that improved the paper. This work was supported by NSF Award ATM-0856007, NASA Award NNX09AK71G, and NASA GSRP Fellowship NNX-09AM38H. NCAR is sponsored by the National Science Foundation.

Edited by: L. M. Russell

\section{References}

Ackerman, S. A. and Strabala K. I.: Satellite remote sensing of $\mathrm{H}_{2} \mathrm{SO}_{4}$ aerosol using the 8- to $12-\mu \mathrm{m}$ window region: Application to Mount Pinatubo, J. Geophys. Res., 99, 18,639-18,649, doi:10.1029/94JD01331, 1994.

Ansmann, A., Wagner, F., Wandinger, U., Mattis, I., Gorsdorf, U., Dier, H. D., and Reichard, J.: Pinatubo aerosol and stratospheric ozone reduction: Observation over central Europe, J. Geophys. Res., 101, 18775-18785, 1996.

Ayers, G. P., Gillett, R. W., and Gras, J. L.: On the vapor-pressure of sulfuric acid, Geophys. Res. Lett., 7, 433-436, 1980.

Bardeen, C. G., Toon, O. B., Jensen, E. J., Marsh, D. R., and Harvey, V. L.: Numerical simulations of the three-dimensional distribution of meteoric dust in the mesosphere and upper stratosphere, J. Geophys. Res., 113, D17202, doi:10.1029/2007jd009515, 2008.

Bardeen, C. G., Toon, O. B., Jensen, E. J., Hervig, M. E., Randall, C. E., Benze, S., Marsh, D. R., and Merkel, A.: Numerical simulations of the three-dimensional distribution of polar mesospheric clouds and comparisons with Cloud Imaging and Particle Size (CIPS) experiment and the Solar Occultation For Ice Experiment (SOFIE) observations, J. Geophys. Res., 115, D10204, doi:10.1029/2009JD012451, 2010.

Barth, M. C., Rasch, P. J., J. T. Kiehl, C. M. Benkovitz, and S. E. Schwartz: Sulfur chemistry in the National Center for Atmospheric Research Community Climate Model: Description, evaluation, features, and sensitivity to aqueous chemistry, J. Geophys. Res.-Atmos., 105, 1387-1415, 2000.

Bauman, J. J., Russell, P. B., Geller, M. A., and Hamill, P.: A stratospheric aerosol climatology from SAGE II and CLAES measurements: 2. Results and comparisons, 1984-1999, J. Geophys. Res., 108, 4383, doi:10.1029/2002JD002993, 2003.

Budyko, M. I.: Climate and Life, 508 pp., Academic, New York, USA, 1974.

Budyko, M. I.: Climatic Changes, 261 pp., AGU, Washington, D.C., USA, 1977.

Chan, T. W. and Mozurkewich, M.: Measurement of the coagulation rate constant for sulfuric acid particles as a function of particle size using tandem differential mobility analysis, J. Aerosol Sci., 32, 321-339, 2001.

Considine, D. B., Douglass, A. R., Connell, P. S., Kinnison, D. E., and Rotman, D. A.: A polar stratospheric cloud parameterization for the three-dimensional model of the global modeling initiative and its response to stratospheric aircraft emissions, J. Geophys. Res., 105, 3955-3975, doi:10.1029/1999JD900932, 2000.

Crutzen, P. J.: Albedo enhancement by stratospheric sulfur injections, A contribution to resolve a policy dilemma?, Climatic Change, 77, 211-219, 2006.

Dickinson, R. E.: Climate engineering: A review of aerosol approaches to changing the global energy balance, Clim. Change, 33, 279-290, doi:10.1007/BF00142576, 1996.

Dutton, E. G. and Christy, J. R.: Solar radiative forcing at selected locations and evidence for global lower tropospheric cooling following the eruptions of El Chichón and Pinatubo, Geophys. Res. Lett., 19, 2313-2316, doi:10.1029/92GL02495, 1992.

English, J. M., Toon, O. B., Mills, M. J., and Yu, F.: Microphysical simulations of new particle formation in the upper troposphere and lower stratosphere, Atmos. Chem. Phys., 11, 9303-9322, doi:10.5194/acp-11-9303-2011, 2011.

English, J. M., Toon, O. B., and Mills, M. J.: Microphysical simulations of large volcanic eruptions: Pinatubo and Toba, J. Geophys. Res., in preparation, 2012.

Fan, T. and Toon, O. B.: Modeling sea-salt aerosol in a coupled climate and sectional microphysical model: mass, optical depth and number concentration, Atmos. Chem. Phys., 11, 4587-4610, doi:10.5194/acp-11-4587-2011, 2011.

Forster, P., V. Ramaswamy, P. Artaxo, T. Berntsen, R. Betts, D. W. Fahey, J. Haywood, J. Lean, D. C. Lowe, G. Myhre, J. Nganga, R. Prinn, G. Raga, M. Schulz and R. Van Dorland, Changes in Atmospheric Constituents and in Radiative Forcing, in: Climate Change 2007: The Physical Science Basis, Contribution of Working Group I to the Fourth Assessment Report of the Intergovernmental Panel on Climate Change, edited by: Solomon, S., Qin, D., Manning, M., Chen, Z., Marquis, M., Averyt, K. B., Tignor, M. and Miller, H. L., Cambridge University Press, Cambridge, United Kingdom and New York, NY, USA, 2007.

Garcia, R. R., Marsh, D. R., Kinnison, D. E., Boville, B. A., and Sassi, F.: Simulation of secular trends in the middle atmosphere, 1950-2003, J. Geophys. Res., 112, D09301, doi:10.1029/2006JD007485, 2007.

Giauque, W. F., Hornung, E. W., Kunzler, J. E., and Rubin, T. R.: The thermodynamic properties of aqueous sulfuric acid solutions and hydrates from 15-degrees-K to 300-degrees-K, J. Amer. Chem. Soc., 82, 62-70, 1960.

Haywood, J. and Boucher, O.: Estimates of the direct and indirect radiative forcing due to tropospheric aerosols: A review, Rev. Geophys., 38, 513-543, doi:10.1029/1999RG000078, 2000.

Heckendorn, P., Weisenstein, D., Fueglistaler, S., Luo, B. P., Rozanov, E., Schraner, M., Thomason, L. W., and Peter, T.: The impact of geoengineering aerosols on stratospheric temperature and ozone, Environ. Res. Lett., 4, 045108, doi:10.1088/17489326/4/4/045108, 2009.

Hommel R. and Graf, H.-F.: Modelling the size distribution of geoengineered stratospheric aerosols, Atmos. Sci. Lett., 12, 168175, doi:10.1002/asl.285, 2011.

Honisch, B., Ridgwell, A., Schmidt, D. N., Thomas, E., Gibbs, S. J., Sluijs, A., Zeebe, R., Kump, L., Martindale, R. C., Greene, S. E., Kiessling, W., Ries, J., Zachos, J. C., Royer, D. L., Barker, S., Marchitto Jr., T. M., Moyer, R., Pelejero, C., Ziveri, P., Foster, G. L., and Williams, B.: The geological record of ocean acidification, Science, 335, 1058-1063, doi:10.1126/science.1208277, 2012. 
IPCC: Climate Change 2007: The Physical Science Basis, Contribution of Working Group I to the Fourth Assessment Report of the Intergovernmental Panel on Climate Change, edited by: Solomon, S., Qin, D., Manning, M., Chen, Z., Marquis, M., Averyt, K. B.,Tignor, M., and Miller, H. L., Cambridge Univ. Press, Cambridge, UK, 2007.

Kravitz, B., Robock, A., Oman, L., Stenchikov, G., and Marquardt, A. B.: Sulfuric acid deposition from stratospheric geoengineering with sulfate aerosols, J. Geophys. Res., 114, D14109, doi:10.1029/2009JD011918, 2009.

Krueger, A. J., Walter, L. S., Bhartia, P. K., Schnetzler, C. C., Krotkov, N. A., Sprod, I., and Bluth, G. J. S.: Volcanic sulfur dioxide measurements from the total ozone mapping spectrometer instruments, J. Geophys. Res., 100, 14057-14076, 1995.

Kulmala, M. and Laaksonen, A.: Binary nucleation of water sulfuric-acid system - comparison of classical-theories with different $\mathrm{H} 2 \mathrm{SO} 4$ saturation vapor-pressures, J. Chem. Phys., 93, 696-701, 1990.

Lamarque, J.-F., Bond, T. C., Eyring, V., Granier, C., Heil, A., Klimont, Z., Lee, D., Liousse, C., Mieville, A., Owen, B., Schultz, M. G., Shindell, D., Smith, S. J., Stehfest, E., Van Aardenne, J., Cooper, O. R., Kainuma, M., Mahowald, N., McConnell, J. R., Naik, V., Riahi, K., and van Vuuren, D. P.: Historical (1850-2000) gridded anthropogenic and biomass burning emissions of reactive gases and aerosols: methodology and application, Atmos. Chem. Phys., 10, 7017-7039, doi:10.5194/acp10-7017-2010, 2010.

Lohmann, U., Karcher, B., and Timmreck, C.: Impact of the Mount Pinatubo eruption on cirrus clouds formed by homogeneous freezing in the ECHAM4 GCM, J. Geophys. Res., 108, 4568, doi:10.1029/2002JD003185, 2003.

Luo, M., Russell III, J. M., and Huang, T. Y. W.: Halogen Occultation Experiment observations of the quasi-biennial oscillation and the effects of Pinatubo aerosols in the tropical stratosphere, J. Geophys. Res., 102, 19187-19198, doi:10.1029/97JD01015, 1997.

Mills, M. J., Toon, O. B., Turco, R. P., Kinnison, D. E., and Garcia, R. R.: Massive global ozone loss predicted following regional nuclear conflict, PNAS, 105, 5307-5312, doi:10.1073/pnas.0710058105, 2008.

Minnis, P., Harrison, E. F., Stowe, L. L., Gibson, G. G., Denn, F. M., Doelling, D. R., and Smith Jr., W. L.: Radiative climate forcing by the Mount Pinatubo eruption, Science, 259, 1411-1415, 1993.

Niemeier, U., Timmreck, C., Graf, H.-F., Kinne, S., Rast, S., and Self, S.: Initial fate of fine ash and sulfur from large volcanic eruptions, Atmos. Chem. Phys., 9, 9043-9057, doi:10.5194/acp9-9043-2009, 2009.

Niemeier, U., Schmidt, H., and Timmreck, C.: The dependency of geoengineered sulfate aerosol on the emission strategy, Atmos. Sci. Lett., 12, 189-194, doi:10.1002/as1.304, 2011.

Palmer, K. F. and Williams, D.: Optical constants of sulfuric acid; Application to the clouds of Venus?, Appl. Optics, 14, 208-219, 1975.

Pan, L. L., Randel, W. J., Gary, B. L., Mahoney, M. J., and Hintsa, E. J.: Definitions and sharpness of the extratropical tropopause: A trace gas perspective, J. Geophys. Res., 109, D23103, doi:10.1029/2004JD004982, 2004.

Pierce, J. R., Weisenstein, D. K., Heckendorn, P., Peter, T., and Keith, D. W.: Efficient formation of stratospheric aerosol for cli- mate engineering by emission of condensible vapor from aircraft, Geophys. Res. Lett., 37, L18805, doi:10.1029/2010GL043975, 2010.

Pinto, J. P., Turco, R. P., and Toon, O. B.: Self-limiting physical and chemical effects in volcanic eruption clouds, J. Geophys. Res., 94, 11165-11174, 1989.

Pitts, M. C. and Thomason, L. W.: The impact of the eruptions of Mount Pinatubo and CERRO Hudson on Antarctic aerosol levels during the 1991 austral spring, Geophys. Res. Lett., 20, 24512454, doi:10.1029/93GL02160, 1993,

Pollack, J. B., Toon, O. B., Sagan, C., Baldwin, B., Summers, A., and Van Camp, W.: Stratospheric Aerosols and Climatic Change, Nature, 236, 551-555, 1976.

Prather, M.: Catastrophic loss of stratospheric ozone in dense volcanic clouds, J. Geophys. Res., 97, 10187-10191, 1992.

Rasch, P. J., Crutzen, P. J., and Coleman, D. B.: Exploring the geoengineering of climate using stratospheric sulfate aerosols: The role of particle size, Geophys. Res. Lett., 35, L02809, doi:10.1029/2007GL032179, 2008.

Read, W. G., Froidevaux, L., and Waters, J. W.: Microwave limb sounder measurements of stratospheric $\mathrm{SO}_{2}$ from the Mt. Pinatubo volcano, Geophys. Res. Lett., 20, 1299-1302, 1993.

Robock, A., Oman, L., and Stenchikov, G. L.: Regional climate responses to geoengineering with tropical and Arctic $\mathrm{SO}_{2}$ injections, J. Geophys. Res.-Atmos., 113, D16101, doi:10.1029/2008JD010050, 2008.

Ross, M., Mills, M., and Toohey, D.: Potential climate impact of black carbon emitted by rockets, Geophys. Res. Lett., 37, L24810, doi:10.1029/2010GL044548, 2010.

Sabinina, A. L. and Terpugow, L.: Die oberflächenspannung de systems schwefelsaure-wasser, Z. Phys. Chem. A, 173, 237-241, 1935.

Sato, M., Hansen, J. E., McCormick, M. P., and Pollack, J. B.: Stratospheric aerosol optical depths, 1850-1990, J. Geophys. Res., 98, 22987-22994, 1993.

Smith, S. J., van Aardenne, J., Klimont, Z., Andres, R. J., Volke, A., and Delgado Arias, S.: Anthropogenic sulfur dioxide emissions: 1850-2005, Atmos. Chem. Phys., 11, 1101-1116, doi:10.5194/acp-11-1101-2011, 2011.

Solomon, S., Daniel, J. S., Sanford, T. J., Murphy, D. M., Plattner, G.-K., Knutti, R., and Friedlingstein, P.: Persistence of climate changes due to a range of greenhouse gases, Proc. Natl Acad. Sci., 107, 18354-18359, doi:10.1073, 2010.

Song, N., Starr, D. O'C., Wuebbles, D. J., Williams, A., and Larson, S.: , Volcanic aerosols and interannual variation of high level clouds, Geophys. Res. Lett., 23, 2657-2660, 1996.

Stenchikov, G., Kirchner, I., Robock, A., Graf, H. F., Antuna, J. C., Grainger, R. G., Lambert, A., and Thomason, L.: Radiative forcing from the 1991 Mount Pinatubo volcanic eruption, J. Geophys. Res., 103, 13837-13857, 1998.

Su, L. and Toon, O. B.: Saharan and Asian dust: similarities and differences determined by CALIPSO, AERONET, and a coupled climate-aerosol microphysical model, Atmos. Chem. Phys., 11, 3263-3280, doi:10.5194/acp-11-3263-2011, 2011.

Tabazadeh, A., Toon, O. B., Clegg, S. L., and Hamill, P.: A new parameterization of $\mathrm{H}_{2} \mathrm{SO}_{4} / \mathrm{H}_{2} \mathrm{O}$ aerosol composition: Atmospheric implications, Geophys. Res. Lett., 24, 15, 1931-1934, 1997. 
Textor, C., Schulz, M., Guibert, S., Kinne, S., Balkanski, Y., Bauer, S., Berntsen, T., Berglen, T., Boucher, O., Chin, M., Dentener, F., Diehl, T., Easter, R., Feichter, H., Fillmore, D., Ghan, S., Ginoux, P., Gong, S., Grini, A., Hendricks, J., Horowitz, L., Huang, P., Isaksen, I., Iversen, I., Kloster, S., Koch, D., Kirkevag, A., Kristjansson, J. E., Krol, M., Lauer, A., Lamarque, J. F., Liu, X., Montanaro, V., Myhre, G., Penner, J., Pitari, G., Reddy, S., Seland, Ø., Stier, P., Takemura, T., and Tie, X.: Analysis and quanti?cation of the diversities of aerosol life cycles within AeroCom, Atmos. Chem. Phys., 6, 1777-1813, doi:10.5194/acp-61777-2006, 2006.

Tilmes, S., Garcia, R. R., Kinnison, D. E., Gettelman, A., and Rasch, P. J.: Impact of geo-engineered aerosols on the troposphere and stratosphere, J. Geophys. Res., 114, D12305, doi:10.1029/2008JD011420, 2009.

Toon, O. B., Turco, R. P., Westphal, D., Malone, R., and Liu, M. S.: A multidimensional model for aerosols - description of computational analogs, J. Atmos. Sci., 45, 2123-2143, 1988.
Trenberth, K. E., and Dai, A.: Effects of Mount Pinatubo volcanic eruption on the hydrological cycle as an ana$\log$ of geoengineering, Geophys. Res. Lett., 34, L15702, doi:10.1029/2007GL030524, 2007.

Wang, P. H., Minnis, P., and Yue, G. K.: Extinction coefficient $(1 \mu \mathrm{m})$ properties of high-altitude clouds from solar occultation measurements (1985-1990): Evidence of volcanic aerosol effect, J. Geophys. Res., 100, 3181-3199, 1995.

WMO: Meteorology-A three-dimensional science, WMO Bull., 6, 134-138, 1957.

Zahn, A., Neubert, R., Maiss, M., and Platt, U.: Fate of long-lived trace species near the Northern Hemispheric tropopause: Carbon dioxide, methane, ozone, and sulfur hexafluoride, J. Geophys. Res., 104, 13923-13942, doi:10.1029/1998JD100106, 1999.

Zhao, J. and Turco, R. P.: Nucleation simulations in the wake of a jet aircraft in stratospheric flight, J. Aerosol Sci., 26, 779-795, 1995. 